\title{
Magnesium batteries: Current picture and missing pieces of the puzzle
}

\author{
Robert Dominko $^{\text {a,b,c,*, Jan Bitenc }}{ }^{\text {a, }}$, Romain Berthelot ${ }^{\mathrm{d}, \mathrm{e}}$, Magali Gauthier ${ }^{\mathrm{f}}$, Gioele Pagot ${ }^{\mathrm{g}, \mathrm{h}}$, \\ Vito Di Noto ${ }^{g, h}$ \\ ${ }^{a}$ National Institute of Chemistry, Hajdrihova 19, 1000, Ljubljana, Slovenia \\ ${ }^{\mathrm{b}}$ Faculty for Chemistry and Chemical Technology, University of Ljubljana, Večna Pot 113, 1000, Ljubljana, Slovenia \\ ${ }^{\mathrm{c}}$ Alistore-European Research Institute, CNRS FR 3104, Hub de l'Energie, Rue Baudelocque, 80039, Amiens, France \\ ${ }^{\mathrm{d}}$ ICGM, Université de Montpellier, CNRS, Montpellier, France \\ ${ }^{\mathrm{e}}$ Réseau sur le Stockage Electrochimique de l'Energie (RS2E), CNRS, Amiens, France \\ ${ }^{\mathrm{f}}$ Université Paris-Saclay, CEA, CNRS, NIMBE, LEEL, 91191, Gif-sur-Yvette, France \\ ${ }^{g}$ Section of Chemistry for the Technology (ChemTech), Department of Industrial Engineering, University of Padova, Via Marzolo 9, I-35131 Padova (PD), Italy \\ ${ }^{\text {h }}$ Centro Studi di Economia e Tecnica dell'Energia Giorgio Levi Cases, Via Marzolo 9, I-35131 Padova (PD), Italy
}

\section{H I G H L I G H T S}

- A critical overview on electrolytes, anode and cathode materials for $\mathrm{Mg}$ batteries.

- Volumetric and gravimetric energy densities are calculated for realistic conditions.

- Continuous research with a focus on understanding of interphases is required.

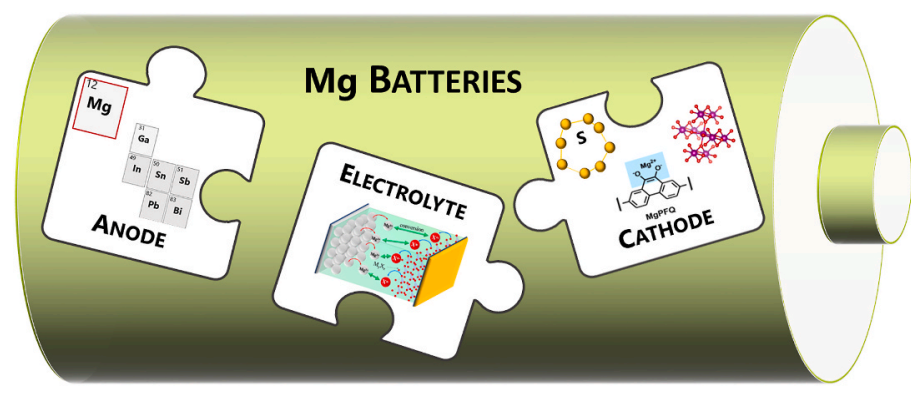

\section{A R T I C L E I N F O}

\section{Keywords:}

Magnesium

Electrolyte

Cathode

Anode

Review

Energy density

\begin{abstract}
A B S T R A C T
Rechargeable magnesium batteries are gaining a lot of interest due to promising electrochemical features, which, at least in theory, are comparable than those of Li-ion batteries. Such performance metrics can be achieved by using thin metal foils or high-capacity alloys coupled with suitable electrolytes enabling a high Coulombic efficiency and use of a high energy density cathode materials. All three components significantly influence electrochemical characteristics and energy density of rechargeable magnesium batteries. Although there are many reports showing progress in the cyclability and stability of different systems, only few cathode materials promise possible commercialization. Remaining issues with efficiency, magnesium anode processing and electrolyte compatibility with cell housing are preventing faster development of technology with high possible impact on the future battery landscape. In the given perspective paper a critical overview on electrolytes, anode materials and three different classes of cathode materials is reported. Different rechargeable magnesium battery configurations were assumed and their dependence of volumetric energy densities on gravimetric energy densities are provided assuming realistic conditions with optimized electrode thicknesses and loadings, electrode porosity and optimized electrolyte quantity. Although calculated values are attractive, further experimental steps are needed in order to prove these numbers on the lab-scale and small prototype cells.
\end{abstract}

\footnotetext{
* Corresponding author. National Institute of Chemistry, Hajdrihova 19, 1000, Ljubljana, Slovenia.

E-mail address: robert.dominko@ki.si (R. Dominko).
} 


\section{Introduction}

Electrification of different sectors is a driving force for a battery research, where constant efforts are devoted to the improvement of existing and development of new solutions, tailored for the specific applications. Currently, electrification of mobility and renewable energy sectors are dominated by the Li-ion battery (LIB) technology, which depends on resources like lithium, graphite, copper, and some transition metals that are either available in limited quantities and/or geographically unequally distributed. At the same time, novel battery technologies based on the metal anodes with unlimited resources and suitable electronegativity can at least partially substitute LIBs in certain applications. Magnesium batteries are one of the alternative technologies. Magnesium metal is an attractive anode due to the high abundance of magnesium and its volumetric capacity of $3833 \mathrm{mAh} \mathrm{cm}^{-3}$ and gravimetric capacity of $2205 \mathrm{mAh} \mathrm{g}^{-1}$ combined with a low redox potential $\left(-2.37 \mathrm{~V}\right.$ vs. SHE). The divalent character of $\mathrm{Mg}^{2+}$ in oxidation offers two electrons per metal $(\mathrm{Mg})$ compared to only one electron in the case of alkali metals, such as Li and Na. Thus, with a properly designed electrolyte-cathode system, one can expect to obtain practical secondary magnesium batteries (RMB) with an energy density of at least $320 \mathrm{Wh}$ $\mathrm{kg}^{-1}$ or $600 \mathrm{Wh} \mathrm{L}^{-1}$ (Fig. 1). For the sake of clarity of the reader details on the methodology used for determination of these figures of merit are provided in the continuation of this review and in SI file.

The development of RMB is in agreement with the demand of the European Strategic Energy Technology (SET) Plan [1] for sustainable battery technologies with higher energy densities. Required properties can be obtained by using metal electrodes based on multivalent metals, which due to their very high volumetric energy density are of significant interest. Magnesium metal and its alloys play a crucial role in many technological applications such as sacrificial anodes in corrosion protection [2], as lightweight alloys in aeronautics and construction [3] and recently also as negative electrodes in RMB.

In this perspective report, the authors are critically focusing their attention on the three major components of a RMB. Discussion about the different types of anode materials is made in close connection to various types of electrolytes (liquid, solid-state, polymer and ionic liquids based) and finally a section on cathode materials classified on the basis of their electrochemical mechanisms, as insertion, conversion and coordination systems, is provided to complete this perspective. With the respect to the other recently published review papers $[4,5,6,7,8,9,10,11]$, the target of this report is to provide for each component of a RMB a critical assessment, evaluated quantitatively in terms of their potential practical performance in a cell (volumetric and gravimetric energy densities). Results shown in Fig. 1 allow to make a fair comparison between performance of $\mathrm{Mg}$ cells comprising either $\mathrm{Mg}$ foil and alloy anodes, with areal capacities in the range $1-4 \mathrm{mAh} \mathrm{cm}^{-2}$. To obtain the whole picture, parameters such as conductive additives, binders and current collectors are accounted and the electrodes are balanced with a suitable cathode to finally estimate possible energy densities. Our calculations are based on a standard pouch cell stack, with a model close to the ones developed by Mazouzi et al. [12] and Berg et al. [13]. This model (see SI file) considers as input the specific charge and operating potential of the active materials, and takes into account the composition of the composite electrode and the porosity of the electrode/separator system. This latter parameter is crucial for alloy electrodes where a large porosity (55\%) is considered beneficial to alleviate their volume expansion during cycling. For $\mathrm{Mg}$ metal anode, an electrode with $50 \% \mathrm{Mg}$ excess on an Al current collector is used to compensate for possible loss of $\mathrm{Mg}$ upon reactivity with the electrolyte and to provide a proper mechanical strength to the electrode. These estimations give a glimpse as the practical limit of Mg batteries as of today, considering similar stacks and design of batteries as LIBs. Yet, the RMB field needs to gain maturity to assess completely those latter considerations. One has to bear in mind that practical RMB will probably lead to changes in current collectors, separators, electrolytes, etc., that may affect negatively or positively the values presented here.

We compare various cathodes materials in Fig. 1 to cover the large spectrum of compounds that will be described in this perspective paper as well as a hypothetical oxide cathode operating at $3 \mathrm{~V}$ and delivering a capacity of $150 \mathrm{mAh} \mathrm{g}^{-1}$. The historical $\mathrm{Mo}_{6} \mathrm{~S}_{8}$ cathode provides densities values far from what could be commercially attractive. Moving to others sulfide compounds such as $\mathrm{VS}_{4}$ and $\mathrm{MoS}_{2}$ improves gravimetric and volumetric densities, with $\mathrm{MoS}_{2}$ particularly leading to a high volumetric density close to $550 \mathrm{Wh} \mathrm{L}^{-1}$ thanks notably to the high bulk density of $\mathrm{MoS}_{2}$. All combinations based on insertion cathodes materials with operating voltage below $2 \mathrm{~V}$ fall well under the values of current LiBs $\left(\sim 685 \mathrm{Wh} \mathrm{L}^{-1}\right.$ and $280 \mathrm{Wh} \mathrm{kg}^{-1}$ for $4 \mathrm{mAh} \mathrm{cm}^{-2}$ ). Differently, redox active organic materials greatly improve gravimetric densities (up to $250 \mathrm{Wh} \mathrm{kg}^{-1}$ ) but at the expense of quite low volumetric densities, as organic materials possess bulk densities in the range of $1.5 \mathrm{~g} \mathrm{~cm}^{-3}$. Only the sulfur conversion cathode and the hypothetical oxide cathode can compete with Li-ion batteries in terms of gravimetric energy density. The oxide values can be further improved by the discovery of oxide compounds with higher operating voltage and higher bulk density as the values are based here on a bulk density $\sim 3 \mathrm{~g} \mathrm{~cm}^{-3}$. Finally, based on a 4 $\mathrm{mAh} \mathrm{cm}^{-2}$ surface capacity, Mg-sulfur approaches densities of $600 \mathrm{Wh}$ $\mathrm{L}^{-1}$ and $320 \mathrm{Wh} \mathrm{kg}^{-1}$. This corresponds to a sulfur loading of $\sim 4 \mathrm{mg}$ $\mathrm{cm}^{-2}$. If one can envision a loading around $10 \mathrm{mg} \mathrm{cm}^{-2}$, without increasing the electrolyte amount, values as high as $780 \mathrm{Wh} \mathrm{L}^{-1}$ and 440 Wh kg ${ }^{-1}$ could be achieved.
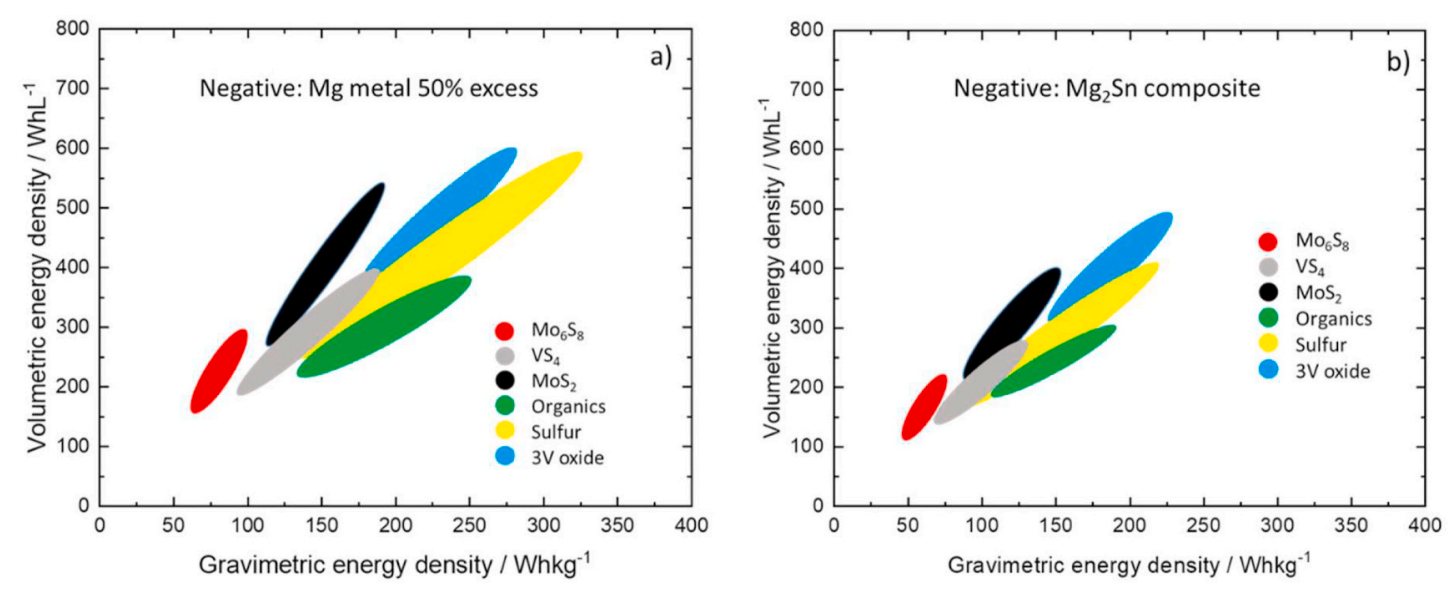

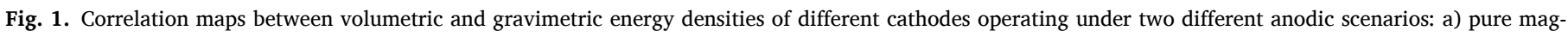
nesium metal with 50 wt $\%$ excess and b) $\mathrm{Mg}_{2} \mathrm{Sn}$ alloy. Figures were derived from calculations presented in Figs. S1 and S2. 


\section{Electrolytes for rechargeable magnesium batteries}

In the last decades several attempts were performed in order to prepare electrolytes with requirements that fit to metallic anode and different types of cathodes. Nevertheless, in order to make RMBs a commercial reality, further breakthroughs in electrolyte technology development are still needed.

The aim of this section is first to provide a brief description of the state of the art in the magnesium ion-conducting electrolytes and secondly, to provide guidelines for devising a rational development of more efficient materials.

\subsection{Liquid-organic solvent electrolytes}

The first attempt on the magnesium metal deposition is attributed to Jolibois, who in 1912 demonstrated the possibility to electrochemically form a $\mathrm{Mg}$ layer on the surface of a metal electrode [14]. In this experiment an electrolyte composed of diethylmagnesium $\left(\mathrm{Et}_{2} \mathrm{Mg}\right)$ and magnesium iodide $\left(\mathrm{MgI}_{2}\right)$ dissolved into diethyl ether $\left(\mathrm{Et}_{2} \mathrm{O}\right)$ was used. This pioneering work opened the door to the development of suitable electrolyte solutions capable of a reversible plating/stripping process of magnesium, but in a limited electrochemical window. More than three quarters of century latter Gregory et al. reported on a series of magnesium electrolytes for RMB [15]. They showed the best performance by using a solution of $\mathrm{Mg}\left[\mathrm{B}\left(\mathrm{Bu}_{2} \mathrm{Ph}_{2}\right)\right]_{2}$ ( $\mathrm{Ph}$ and $\mathrm{Bu}$ represent phenyl and butyl groups, respectively) in tetrahydrofuran (THF) [15]. In the late 90 's, Fauri and Di Noto patented the invention of a RMB including organic solvent electrolytes based on $\delta-\mathrm{MgCl}_{2}[16,17]$. The $\delta-\mathrm{MgCl}_{2}$ salt is characterized by a high crystallographic disorder and has high solubility in organic solvents [18]. Its structure consists of covalently bonded magnesium chloride repeated units that form a sort of polymer chain [19]. The presence of these covalent bonds, which show the typical structure and the electrochemical activity of Grignard reagents, has the advantage to eliminate the high reactivity and instability typically exhibited by the alkyl-magnesium species. In 2000 Aurbach et al. replaced boron derivatives in Grignard reagents with aluminum species [20]. Here, a family of pseudo-Grignard magnesium organohaloaluminate derivatives was investigated, showing that the best material is $\mathrm{Mg}\left(\mathrm{AlCl}_{2} \mathrm{BuEt}\right)_{2}$ in a THF solution. With respect to the organoborate electrolyte developed by Gregory [15], this Grignard, based on an electron-withdrawing derivative (i.e., the organoaluminate core), presented a higher oxidative stability of $2.3 \mathrm{~V} v s . \mathrm{Mg} / \mathrm{Mg}^{2+}$. The coin-cell battery prepared with this electrolyte based on a $\mathrm{Mg}$ metal anode and a $\mathrm{Mo}_{6} \mathrm{~S}_{8}$ Chevrel phase cathode showed long-term cyclability. A magnesium electrolyte based on hexamethyldisilazide magnesium chloride (HMDSMgCl), firstly proposed by Liebenow et al. [21], unfortunately shows a Coulombic efficiency, voltage stability, conductivity and current density inferior to several other magnesium organohaloaluminate electrolytes. On the other hand, those parameters can be improved by addition of $\mathrm{AlCl}_{3}$ (i.e., a Lewis acid) to this non-nucleophilic base [22]. The oxidative stability and the Coulombic efficiency is further improved when the magnesium complex formed in the electrolyte (i.e., $\left.\left[\mathrm{Mg}_{2}(\mu-\mathrm{Cl})_{3} \cdot 6 \mathrm{THF}\right]\left[\mathrm{HMDSAlCl}_{3}\right]\right)$ is crystallized and then re-dissolved into THF. The substitution of $\mathrm{AlCl}_{3}$ with $\mathrm{MgCl}_{2}$, proposed by Liao et al. [23], gives rise to a less reactive and sensitive electrolyte which is able to efficiently deposit and strip magnesium. The formation in solution of [magnesium complexes-Lewis acid molecules-solvent] derivatives (e.g., $\left.\left[\mathrm{Mg}_{\mathrm{m}} \mathrm{Al}_{\mathrm{n}} \mathrm{Cl}_{(2 \mathrm{~m}+3 \cdot \mathrm{n})} \cdot \mathrm{xDME}\right]\right)$, is the basis of two of the best performing electrolytes for $\mathrm{Mg}$ deposition/stripping processes, i.e.: the "All Phenyl Complex" (APC) from Aurbach et al. [24] and the "Magnesium Aluminum Chloride Complex" (MACC) by Doe et al. [25]. The APC electrolyte is obtained by reacting 2 mol of phenylmagnesium chloride ( $\mathrm{PhMgCl})$ with one of aluminum chloride, and then by dissolving the product into THF. On the other hand, MACC is obtained by mixing $\mathrm{MgCl}_{2}$ with $\mathrm{AlCl}_{3}$ (2:1) in DME.

The report of Gregory et al. [15] triggered the subsequent studies on the magnesium organoborate electrolytes which, in 2002, led Aurbach et al. to propose as electrolytes mixtures of $\mathrm{Bu}_{2} \mathrm{Mg}$ (Lewis bases) with different boron-based Lewis acids [26]. In these studies, the best results were achieved using as Lewis acids $\mathrm{BPh}_{3}$ or $\mathrm{BCl}_{3}$, which permitted to obtain electrolytes with an anodic stability of $1.75 \mathrm{~V}$ vs. $\mathrm{Mg} / \mathrm{Mg}^{2+}$. Further improvements were documented by Guo et al. introducing dimethylphenyl (Mes) functionalities in the boron-based Lewis acid, which permitted an extension of the anodic stability up to $3.5 \mathrm{~V} v s$. $\mathrm{Mg} / \mathrm{Mg}^{2+}$ [27]. In the same year, Mohtadi et al. suggested to use a halogen-free electrolyte obtained by dissolving magnesium borohydride in dimethoxyethane (DME) [28]. This electrolyte, despite its successful deposition/stripping process, revealed a quite poor electrochemical performance with an oxidative stability up to $1.5 \mathrm{~V} v \mathrm{~s} . \mathrm{Mg} / \mathrm{Mg}^{2+}$. The same group later was able to increase the oxidation stability of the electrolyte by substituting the borohydride anion with a monocarborane $\left(\mathrm{CB}_{11} \mathrm{H}_{12}^{-}\right)$and by dissolving the resulting magnesium salt into tetraglyme (TEGDME) (Fig. 2a) [29]. Recent results in the magnesium organoborate compounds were obtained by Zhao-Karger et al. [30], who proposed an electrolyte consisting of a magnesium tetrakis(hexafluoroisopropyloxy)borate ( $\left.\mathrm{Mg}\left[\mathrm{B}(\mathrm{HFIP})_{4}\right]_{2}\right)$ salt (Fig. 2b) dissolved into DME (prepared by $\mathrm{Mg}\left(\mathrm{BH}_{4}\right)_{2}$ and hexafluoroisopropanol).

Taking all together, great improvements were achieved in the last three decades for organic liquid electrolytes. Indeed, these materials present ionic conductivities and Coulombic efficiencies close to the actual values of the best performing Li-based organic electrolytes. These latter fundamental cornerstones are the result of a successful implementation of all the cardinal knowledge that was developed over the past years. Indeed, outcomes, starting from Jolibois in 1912 and up to today, revealed common aspects to be considered for designing advanced electrolytes: (i) $\mathrm{Mg}^{2+}$ ions need weak coordinating agents/ ligands, such as halogen anions; and (ii) solvents with a high electrodonating power ensure an optimal solubilization of magnesium ions, which allows for an easier electrochemical deposition. Unfortunately, most of the electrolytes discussed above are based on the volatile and highly flammable ethereal solvents (e.g., THF, DME, etc.), which are incompatible with the current policies of the European Union [1]. Indeed, these electrolytes make the battery unsafe, compromising its environmental cost and life cycle assessment (LCA) [1]. Furthermore, the magnesium electrochemical deposition in these electrolytes still suffer from a generally high overpotential [33] which is diagnostic of the large potential drop in the double layer region and of the sluggish energy efficiency of the final battery.

\subsection{Solid-state electrolytes}

Several attempts were performed to develop solid-state electrolytes (SSEs) for RMB with high conductivity. Unfortunately, the roomtemperature ionic conductivity of these materials is too low for practical applications. The first explored SSE was the $\mathrm{Na}^{+}$superionic conductor (NASICON) doped with $\mathrm{Mg}^{2+}$ ions [34]. Despite the effort devoted to improve these $\mathrm{Mg}^{2+}$-NASICON-type SSEs, their ionic conductivity at high temperature (i.e., $300-800{ }^{\circ} \mathrm{C}$ range) never exceeded the value of $10^{-6} \mathrm{~S} \mathrm{~cm}^{-1}[35,36]$. Ternary spinel chalcogenides were proposed as room-temperature magnesium SSEs, with an overall conductivity value of up to $10^{-5} \mathrm{~S} \mathrm{~cm}^{-1}$ [37], which unfortunately is the result of the superposition of their ionic and electronic conductivities. Magnesium borohydride derivatives, which are promising salts for liquid electrolytes [28] are demonstrated to be very interesting also for the preparation of SSE. Indeed, in complexes such as $\mathrm{Mg}\left(\mathrm{BH}_{4}\right)\left(\mathrm{NH}_{2}\right)$ [38], a $\mathrm{Mg}^{2+}$ conductivity of $1 \cdot 10^{-6} \mathrm{~S} \mathrm{~cm}^{-1}$ at $150{ }^{\circ} \mathrm{C}$ is revealed, which allowed a plating/stripping process onto a Pt electrode with current densities on the order of few $\mu \mathrm{A} \mathrm{cm}{ }^{-2}$. The ionic conductivity of this material was improved by Le Ruyet et al. through optimization of the synthesis parameters (e.g., the ball-milling speed) [39]. Amino-complexes of magnesium borohydride were proposed also by Roedern et al. substituting $\mathrm{NH}_{2}^{-}$with a neutral bidentate 

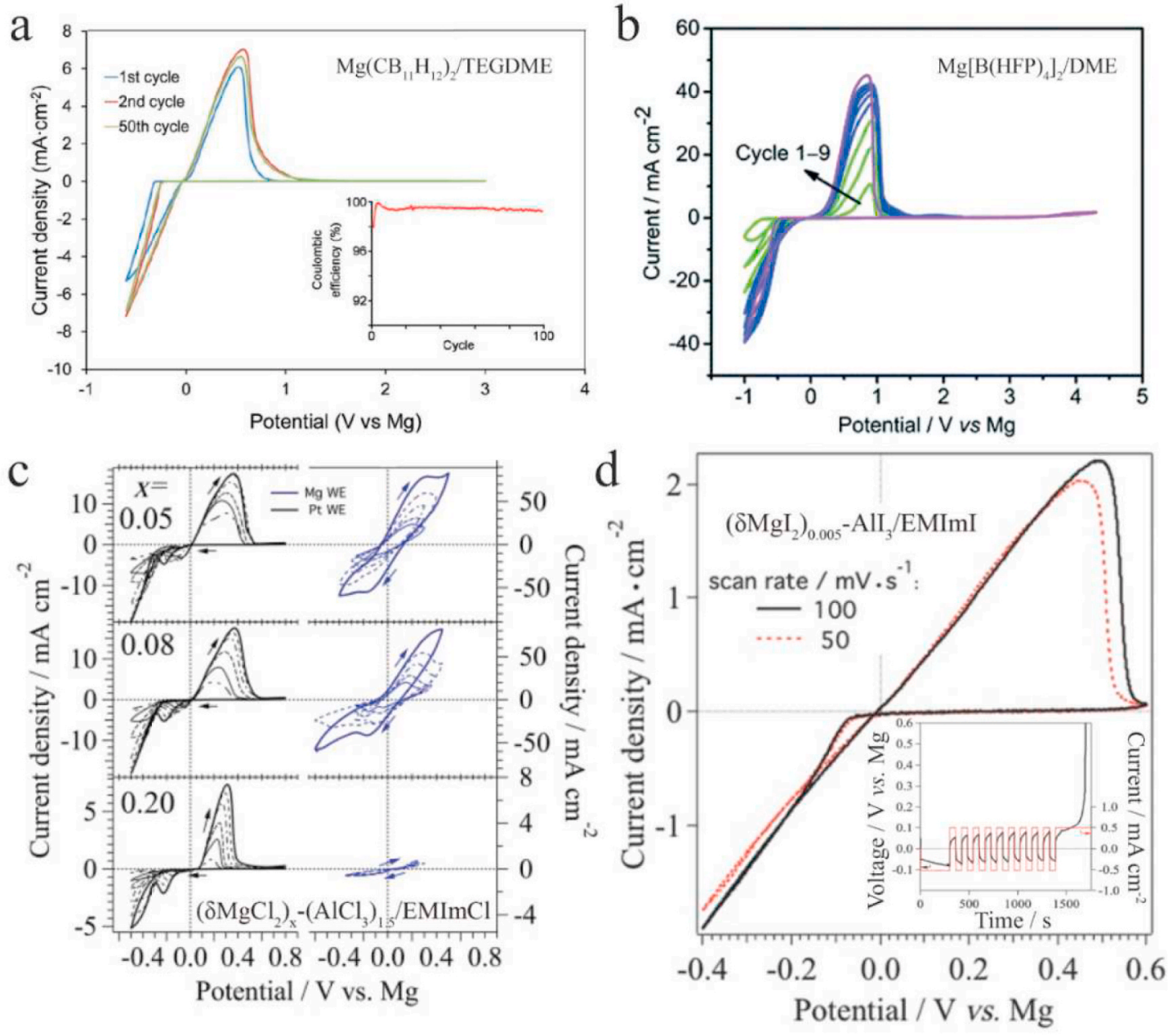

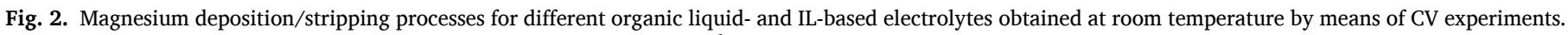

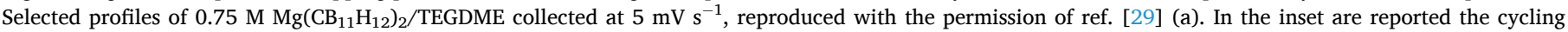

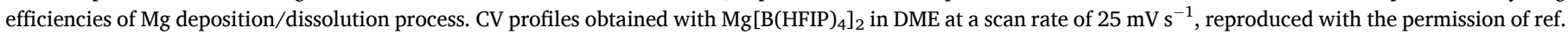

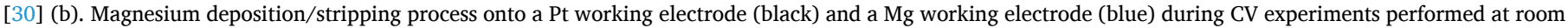

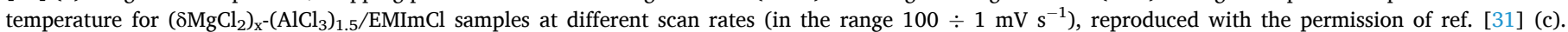

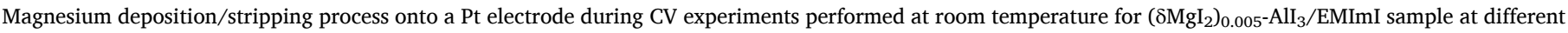

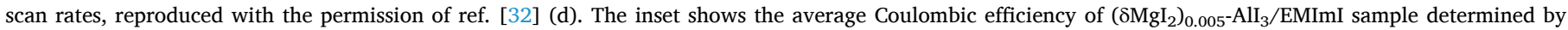

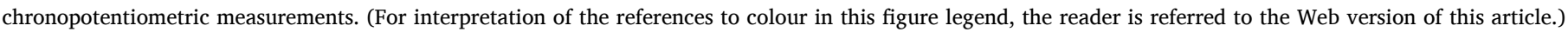

ethylenediamine ligand (en) [40]. Finally, a sort of $\mathrm{Mg}^{2+}$-conducting gel electrolyte was proposed by Aubrey et al. [41], by impregnating with several liquid electrolytes different types of hybrid inorganic-organic electrolytes (HIOE) [42], named also as metal-organic frameworks (MOF). In particular, the best performing hybrid electrolyte consists of a mixture of magnesium 4,40-dioxidobiphenyl-3,30-dicarboxylate $\left(\mathrm{Mg}_{2}\right.$ (dobpdc) $)$ and $\mathrm{Mg}\left(\mathrm{OPhCF}_{3}\right)_{2} / \mathrm{Mg}(\mathrm{TFSI})_{2}$ dissolved in triglyme (TEG) which, at room-temperature, exhibits a conductivity of $2.5 \cdot 10^{-4} \mathrm{~S}$ $\mathrm{cm}^{-1}$.

However, regardless of significant results achieved in SSEs, there is still a big room for their improvements. Indeed, up today for these materials, no reasonable conductivity and electrochemical activity is proved at room temperature.

\subsection{Polymer electrolytes}

The conductivity of polymer electrolytes (PEs) is generally lower than that of liquid electrolytes, and higher than values of SSEs [42]. In spite of the number of previous attempts in PEs [43,44], the threshold of $10^{-5} \mathrm{~S} \mathrm{~cm}^{-1}$ at room temperature was approached for the first time in the late 90 's $[16,17,45-49]$, just before studies on organoborate liquid electrolytes previously described [26]. In details, Di Noto et al. demonstrated a room-temperature ionic conductivity of $1.9 \cdot 10^{-5} \mathrm{~S} \mathrm{~cm}^{-1}$ with an electrolyte obtained by doping poly(ethylene glycol) (PEG) with $\delta \mathrm{MgCl}_{2}[16,17,45]$. At the same time, Ramalingaiah et al. obtained a solid state polymer electrolyte with a conductivity of $1.34 \cdot 10^{-5} \mathrm{~S} \mathrm{~cm}^{-1}$ by dissolving $\mathrm{Mg}\left(\mathrm{NO}_{3}\right)_{2}$ salt into a poly(ethylene oxide) (PEO) matrix [48]. Different other groups [50, 51] followed this direction adding $\mathrm{Mg}$ $\left(\mathrm{NO}_{3}\right)_{2}$ into polymer electrolytes achieving the best performance (conductivity of $1.71 \cdot 10^{-3} \mathrm{~S} \mathrm{~cm}^{-1}$ and an oxidative stability of $2.6 \mathrm{~V} v s$. $\mathrm{Mg} / \mathrm{Mg}^{2+}$ ) for an electrolyte based on a polymer blend of PVA and poly (acrylonitrile) (PAN) [52]. In addition to $\mathrm{Mg}\left(\mathrm{NO}_{3}\right)_{2}$, Manjuladevi et al. studied electrolytes based on $\mathrm{Mg}\left(\mathrm{ClO}_{4}\right)_{2}$ and a PVA-PAN PE polymer matrix [53]. In this case, a lower ionic conductivity (i.e., $2.94 \cdot 10^{-4} \mathrm{~S}$ $\mathrm{cm}^{-1}$ ) and a narrower electrochemical stability (i.e., $2.5 \mathrm{~V}$ vs. $\mathrm{Mg} / \mathrm{Mg}^{2+}$ ) were obtained, which demonstrated that, with respect to $\mathrm{ClO}_{4}^{-}, \mathrm{NO}_{3}^{-}$ anion is a better choice despite both anions are not compatible with metallic magnesium. PEs based on magnesium triflate $\left(\mathrm{MgTf}_{2}\right)$ and several other polymer matrices, such as PVA [54], PVdF/HFP [55], and PEO are investigated [56]. Among all, the highest conductivity was achieved by preparing PEs based on PVdF/HFP $\left(1 \cdot 10^{-3} \mathrm{~S} \mathrm{~cm}^{-1}\right)$ [55]. Furthermore, in order to improve the electrochemical performance, 
several electrolytes are proposed in literature, which are obtained by doping classic PEs with suitable low molecular organic molecules [57, 58]. In those materials, the addition of solvents enables a higher conductivity, but unfortunately compromises the safety and stability advantages typically offered by a polymer electrolyte matrix. Thus, this approach seems to be of marginal interest for practical applications in real batteries.

\subsection{Ionic liquid-based electrolytes}

Use of ionic liquids (ILs) as a solvent for Mg electrolytes was firstly proposed by NuLi et al. in 2005 [59,60]. In these reports, $\mathrm{MgTf}_{2}$ salt was dissolved into a 1-butyl-3-methylimidazolium tetrafluoroborate $\left(\mathrm{BMImBF}_{4}\right)$ ionic liquid, and deposition and stripping processes were demonstrated by means of CV studies. These results later were disproved by Cheek et al. [61] and by Aurbach et al. [62], who attributed the events observed by NuLi to the electrolyte decomposition. Actually, electrolytes for $\mathrm{Mg}$ batteries based on $\mathrm{BF}_{4}^{-}$anions are well-known for their poor electrochemical activity, even if they are characterized by a promising ionic conductivity [63]. Better results were achieved by Sutto et al., who used an IL based on 1,2-dimethyl-3-n-propylimidazolium bis (trifluoromethanesulfonyl)imide (MMPI-TFSI) to dissolve $\mathrm{Mg}(\mathrm{TFSI})_{2}$ salt with ionic conductivity up to $1.75 \cdot 10^{-3} \mathrm{~S} \mathrm{~cm}^{-1}$ [64]. Unfortunately, no plating/stripping process of magnesium onto a Pt electrode was revealed with this electrolyte. The substitution with 1-butyl-1-methylpyrrolidinium $\left(\mathrm{Pyr}_{14}^{+}\right.$) or N-(2-methoxyethyl)-N-methylpyrrolidinium $\left(\mathrm{PYR}_{1201}^{+}\right.$) of the imidazolium cation of the IL resulted in an electrolyte with improved ionic conductivity (i.e., from $2.2 \cdot 10^{-3}$ to $3.2 \cdot 10^{-3} \mathrm{~S}$ $\mathrm{cm}^{-1}$ ) [65], which is able to insert/deinsert $\mathrm{Mg}^{2+}$ into/from a $\mathrm{V}_{2} \mathrm{O}_{5}$ aerogel electrode at room temperature [66]. The reversible $\mathrm{Mg}$ deposition/stripping process on a Pt electrode using a pure IL-based electrolyte was for the first time demonstrated by Bertasi et al. in 2013 using 1-ethyl-3-methylimidazolium (EMIm $\left.{ }^{+}\right)$-based ILs $[31,32,67,68]$. In this case, ternary systems of the type $\mathrm{EMImX} /\left(\mathrm{MX}_{\mathrm{n}}\right)_{\mathrm{m}} /\left(\delta \mathrm{MgX}_{2}\right)_{\mathrm{z}}\left(\right.$ where $\mathrm{X}=\mathrm{Cl}^{-}$or $\mathrm{I}^{-}$and $\mathrm{M}=\mathrm{Al}^{3+}$ or $\mathrm{Ti}^{4+}$ ) were prepared which demonstrated that the concurrent introduction into the IL of the metal halide component (i.e., $\mathrm{MX}_{\mathrm{n}}$ ) and of the $\delta$ form of magnesium halides [18] provides a synergistic effect able to raise both the magnesium salt solubility and the electrochemical activity of the electrolyte. Indeed, these electrolytes present: (i) a conductivity at room-temperature of up to $5.5 \cdot 10^{-3} \mathrm{~S} \mathrm{~cm}^{-1}$; (ii) an efficient ability to deposit $\mathrm{Mg}$ with a very low overpotential $(<100 \mathrm{mV}$, see Fig. 2c and d); (iii) a high CE (up to $99.94 \%$, see the inset of Fig. 2d); and (iv) a current density in the order of $10 \mathrm{~mA} \mathrm{~cm}^{-2}$. Here, $\mathrm{Mg}$ is co-deposited with the other co-metals (i.e., $\mathrm{Al}$ or Ti) forming metal alloys at a reduction potential which is downshifted towards $0 \mathrm{~V} v s . \mathrm{Mg} / \mathrm{Mg}^{2+}$. In this way, an enhancing of the specific energy of the cell is obtained which, for the first time, allowed to assemble and cycle efficiently a $\mathrm{Mg}$ secondary battery based on a pure ionic liquid electrolyte [31].

\subsection{Perspectives in electrolytes for magnesium batteries}

A summary of the electrochemical performance of the above discussed Mg-ion conducting electrolytes is given in Table 1.

Liquid electrolytes based on organic solvents or ionic liquids are up

Table 1

Electrochemical properties of the electrolytes discussed in this work.

\begin{tabular}{|c|c|c|c|c|c|c|c|}
\hline Type & Salt & Solvent & Overp. Mg dep./mV & ${ }^{\mathrm{a}} \mathrm{CE}(\%)$ & $\begin{array}{l}{ }^{\mathrm{b}} \sigma \text { at r.t. } \\
/ \mathrm{S} \mathrm{cm}{ }^{-1}\end{array}$ & ${ }^{\mathrm{c}}$ Ox. stability/V vs. Mg & Ref. \\
\hline \multirow[t]{12}{*}{ Liquid-organic } & $\operatorname{Mg}\left[\mathrm{B}\left(\mathrm{Bu}_{2} \mathrm{Ph}_{2}\right)\right]_{2}$ & THF & - & - & $1 \cdot 10^{-3}$ & - & [15] \\
\hline & $\mathrm{Bu}_{2} \mathrm{Mg}-\mathrm{BPh}_{3}$ & THF & 200 & $93(\mathrm{CV})$ & - & $1.30(\mathrm{Pt})$ & {$[26]$} \\
\hline & $\mathrm{Bu}_{2} \mathrm{Mg}-\mathrm{BCl}_{3}$ & THF & 210 & $93(\mathrm{CV})$ & - & $1.75(\mathrm{Pt})$ & {$[26]$} \\
\hline & $\mathrm{Mes}_{3} \mathrm{~B}-(\mathrm{PhMgCl})_{2}$ & THF & 500 & $98.96(\mathrm{CP})$ & $2 \cdot 10^{-3}$ & $3.5(\mathrm{Pt})$ & {$[27]$} \\
\hline & $\mathrm{Mg}\left(\mathrm{BH}_{4}\right)_{2}$ & DME & 350 & $67(\mathrm{CV})$ & - & $1.5(\mathrm{Pt})$ & {$[28]$} \\
\hline & $\mathrm{Mg}\left(\mathrm{CB}_{11} \mathrm{H}_{12}\right)_{2}$ & TEGDME & 310 & $94.4(\mathrm{CV})$ & $1.8 \cdot 10^{-3}$ & $3.8(\mathrm{Pt})$ & [29] \\
\hline & $\mathrm{Mg}\left[\mathrm{B}(\mathrm{HFIP})_{4}\right]_{2}$ & DME & 500 & $>98(\mathrm{CP})$ & $6.8 \cdot 10^{-3}$ & $3.5(\mathrm{Pt})$ & [30] \\
\hline & $\mathrm{Mg}\left(\mathrm{AlCl}_{2} \mathrm{BuEt}\right)_{2}$ & THF & 290 & $99.6(\mathrm{QCM})$ & ca. $10^{-3}$ & $2.3(\mathrm{Pt})$ & [20] \\
\hline & ${\mathrm{HMDSMgCl}-\mathrm{AlCl}_{3}}_{3}$ & THF & 250 & $95(\mathrm{CV})$ & - & $2.4(\mathrm{Pt})$ & {$[22]$} \\
\hline & 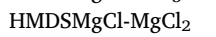 & THF & 270 & $99(\mathrm{CV})$ & $2 \cdot 10^{-4}$ & $2.8(\mathrm{Pt})$ & [23] \\
\hline & $\mathrm{PhMgCl}-\mathrm{AlCl}_{3}$ & THF & 195 & $100(\mathrm{CV})$ & $4 \cdot 10^{-3}$ & $3.5(\mathrm{Pt})$ & {$[24]$} \\
\hline & $\mathrm{MgCl}_{2}-\mathrm{AlCl}_{3}$ & DME & 450 & $98.8(\mathrm{CP})$ & $2 \cdot 10^{-3}$ & $3.1(\mathrm{Pt})$ & [25] \\
\hline \multirow[t]{6}{*}{ Solid } & Mg-NASICON & - & - & - & $10^{-6}\left(300^{\circ} \mathrm{C}\right)$ & - & {$[35,36]$} \\
\hline & $\mathrm{Mg}\left(\mathrm{BH}_{4}\right)\left(\mathrm{NH}_{2}\right)$ & - & - & - & $1 \cdot 10^{-6}\left(150^{\circ} \mathrm{C}\right)$ & - & [38] \\
\hline & $\mathrm{Mg}\left(\mathrm{BH}_{4}\right)\left(\mathrm{NH}_{2}\right)$ & - & - & - & $3 \cdot 10^{-6}\left(100^{\circ} \mathrm{C}\right)$ & - & [39] \\
\hline & $\mathrm{Mg}\left(\mathrm{BH}_{4}\right)_{2}(\mathrm{en})_{1}$ & - & - & - & $5 \cdot 10^{-8}$ & - & {$[40]$} \\
\hline & $\mathrm{Mg}\left(\mathrm{BH}_{4}\right)_{2}\left(\mathrm{NH}_{3} \mathrm{BH}_{3}\right)_{2}$ & & & & $8.4 \cdot 10^{-5}\left(40^{\circ} \mathrm{C}\right)$ & & [69] \\
\hline & $\mathrm{Mg}_{2}(\mathrm{dobpdc})$ & TEGDME & - & - & $2.5 \cdot 10^{-4}$ & - & [41] \\
\hline \multirow[t]{11}{*}{ Polymer } & $\delta \mathrm{MgCl}_{2}$ & PEG & - & - & $1.9 \cdot 10^{-5}$ & - & [45] \\
\hline & $\mathrm{Mg}\left(\mathrm{NO}_{3}\right)_{2}$ & PEO & - & - & $1.34 \cdot 10^{-5}$ & - & [48] \\
\hline & $\mathrm{Mg}\left(\mathrm{NO}_{3}\right)_{2}$ & PVA-PEG & - & - & $9.63 \cdot 10^{-5}$ & - & [42] \\
\hline & $\mathrm{Mg}\left(\mathrm{NO}_{3}\right)_{2}$ & PEO-PVP & - & - & $5.8 \cdot 10^{-4}$ & - & [43] \\
\hline & $\mathrm{Mg}\left(\mathrm{NO}_{3}\right)_{2}$ & PVA-PAN & - & - & $1.71 \cdot 10^{-3}$ & 2.6 (SS) & [52] \\
\hline & $\mathrm{Mg}\left(\mathrm{ClO}_{4}\right)_{2}$ & PVA-PVP & 1000 & - & $1.1 \cdot 10^{-4}$ & 3.8 (SS) & [45] \\
\hline & $\mathrm{Mg}\left(\mathrm{ClO}_{4}\right)_{2}$ & PVA-PAN & - & - & $2.94 \cdot 10^{-4}$ & 2.5 (SS) & {$[53]$} \\
\hline & $\mathrm{Mg}\left(\mathrm{ClO}_{4}\right)_{2}$ & PVdF/HFP-PVAc & - & - & $1.6 \cdot 10^{-5}$ & 2.0 (SS) & [47] \\
\hline & $\mathrm{MgTf}_{2}$ & PVA & - & - & $5.41 \cdot 10^{-4}$ & - & [54] \\
\hline & $\operatorname{MgTf}_{2}$ & PVdF/HFP & - & - & $1 \cdot 10^{-3}$ & - & [55] \\
\hline & $\operatorname{MgTf}_{2}$ & $\mathrm{PEO}+\mathrm{MgO}$ & - & - & $1.67 \cdot 10^{-5}$ & - & {$[56]$} \\
\hline \multirow[t]{6}{*}{ Ionic liquid } & $\mathrm{Mg}(\mathrm{TFSI})_{2}$ & MMPITFSI & - & - & $1.75 \cdot 10^{-3}$ & - & [64] \\
\hline & $\operatorname{Mg}(\mathrm{TFSI})_{2}$ & PYR $_{14}$ TFSI & - & - & $2.2 \cdot 10^{-3}$ & - & [65] \\
\hline & $\operatorname{Mg}(\mathrm{TFSI})_{2}$ & $\mathrm{PYR}_{1201} \mathrm{TFSI}$ & - & - & $3.2 \cdot 10^{-3}$ & - & {$[65]$} \\
\hline & $\delta \mathrm{MgCl}_{2}-\mathrm{AlCl}_{3}$ & EMImCl & 100 & $98.38(\mathrm{CP})$ & $5.5 \cdot 10^{-3}$ & $2.3(\mathrm{Pt})$ & [31] \\
\hline & $\delta \mathrm{MgI}_{2}-\mathrm{AlI}_{3}$ & EMImI & 70 & 99.94 (CP) & $3.0 \cdot 10^{-4}$ & $1.0(\mathrm{Pt})$ & [32] \\
\hline & $\delta \mathrm{MgCl}_{2}-\mathrm{TiCl}_{4}$ & EMImCl & 30 & $99.3(\mathrm{CP})$ & $2.5 \cdot 10^{-5}$ & $1.6(\mathrm{Pt})$ & [68] \\
\hline
\end{tabular}

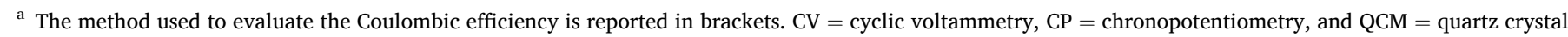
microbalance.

b Temperature in brackets is for conductivity values not measured at room-temperature.

c The working electrode to evaluate the oxidative stability is reported in brackets (S.S. = Stainless Steel). 
to now the best performing materials for Mg deposition/stripping processes. The former electrolytes present a wider electrochemical stability window, whilst the latter group shows a lower overvoltage in the $\mathrm{Mg}$ deposition process, a higher thermal and chemical stability and a negligible flammability. The overview described above highlights that, for the development of future high performing magnesium electrolytes, it is of crucial importance to devise materials: (i) which exhibit a high cationic mobility and with no oxygenated ligands in the matrix; (ii) based on anions, which act as weak coordination ligands for the electroactive metal species composing the cathode. This is necessary to provide a fast and reversible coordination and elimination process of anion species at the interface electrolyte-cathode material.

In a MRB, differently from a LiB, electrolytes on the basis of their chemical compatibility with the cathodic or anodic redox processes (see Fig. 3) can be classified in two groups: (a) electrolytes of the first species (I); and (b) electrolytes of the second species (II). In general, for a discharge process, $\mathrm{Mg}^{2+}$ cations, in the first species electrolytes, are injected: (i) into the electrolyte after an anodic oxidation process; and (ii) into the cathodic active material from the electrolyte after a cathodic reduction event (Fig. 3a) [20,22,23,26-30]. On the other hand, for a discharge process, in the second species electrolytes (II), the ions are concurrently injected into the electrolyte from the electrodes as follows: (i) $\mathrm{Mg}^{2+}$ cations from the anode; and (ii) $\mathrm{X}^{\mathrm{n}-}$ anions from the cathodes owing to the reduction events of the cathodic active materials (Fig. 3b) $[31,32,68]$. To improve the battery performance for electrolytes of

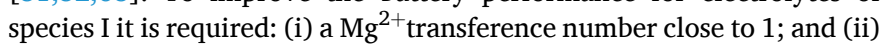
a high compatibility with the interface electrode reactions at both the anode and the cathode side. For the electrochemical reactivity at the $\mathrm{Mg}$ metal anode, no traces of water or of other oxygenated coordination ligands should be present in electrolyte, to avoid any compromise of the anodic reversibility, cyclability and current density [70]. Actually, oxygenated species facilitate the formation on the magnesium metal anode of a compact $\mathrm{MgO}_{\mathrm{x}}(\mathrm{OH})_{\mathrm{y}}$ thin layer, which hinders the anode-electrolyte charge exchange processes promoting on its surface the growth of dendrites.

As demonstrated by Novak et al. in the early 90's [71,72], water is necessary in the cathodic side in order to exchange efficiently and with a high reversibility magnesium between the solid cathode active material and the electrolyte by insertion and de-insertion processes. Indeed, water molecules are able to exfoliate the cathode layered structure and to enhance the $\mathrm{Mg}^{2+}$ diffusion into the bulk cathode materials by solvating the ions and facilitating their solid-state migration events [73, 74]. These latter phenomena reduce the electrode overpotential and the energy loss events, thus increasing the efficiency of the interfacial charge transfer processes $[73,74]$. Taking all together, the state of art results demonstrate that the development of a magnesium battery of species I is a very difficult target, as it requires electrolytes able to reconcile the "Devil" (anode) with the "Holy Water" (cathode) electrochemistry. A compromise can be likely achieved by developing: (i) electrolytes stable and highly conducting which are based on non-oxygenated matrices; or (ii) in general, electrode materials which are highly performing and chemically stable in the same electrolyte environment. A different scenario is offered by the electrolytes of species II which, as demonstrated in the above described overview, are mainly consisting of IL-based materials [63,31,32,67,68]. In this case, no oxygenated electrolytes are used, and the anode redox processes show a reversible performance and a high electrochemical stability. In details, in this case: (i) the overall conductivity in electrolyte is mainly mediated by the anion migration events [31,32]; and (ii) the cathode material is a redox system which, differently from species I electrolyte batteries, is characterized by anion exchange processes at the electrolyte-electrode material interface (see Fig. 3b). Therefore, improvements in species II electrolytes can be achieved if they are devised and developed to act (Fig. 3b): (i) for a discharge process, as an "absorbing sponge" with a high ion exchange capacity for both the anions and the cations; and (ii) for a charge process, as a fast ion providing sink (both of anions and cations) to the electrodes. This concept was recently proved [75] by developing a second generation electroactive cathodic materials able to provide efficient and reversible electrochemical redox processes; and electrolytes with a high anionic and cationic exchange capacity to increase the overall specific energy of the final battery.

Taking all together, results outlined here seem to demonstrate that until today, species II electrolytes are the most promising materials able to solve the "Devil" and the "Holy Water" dilemma of Mg-batteries on the expense of larger quantities of electrolyte added to the cell.

\section{Anode materials}

\subsection{Metallic magnesium anode}

Typically, the use of metal electrodes is limited by their thermodynamic stability in electrolytes. Indeed, most of metals, at least under certain conditions, form an electron blocking passivation layer, which can be either ion conductive or ion blocking. Additionally, in electrolytes with low transference number for cations, the interplay between uniform ion transport, roughness of metal electrodes and wetting properties of separators induce non-homogenous electrical fields between electrodes which lead during continuous electro-dissolution
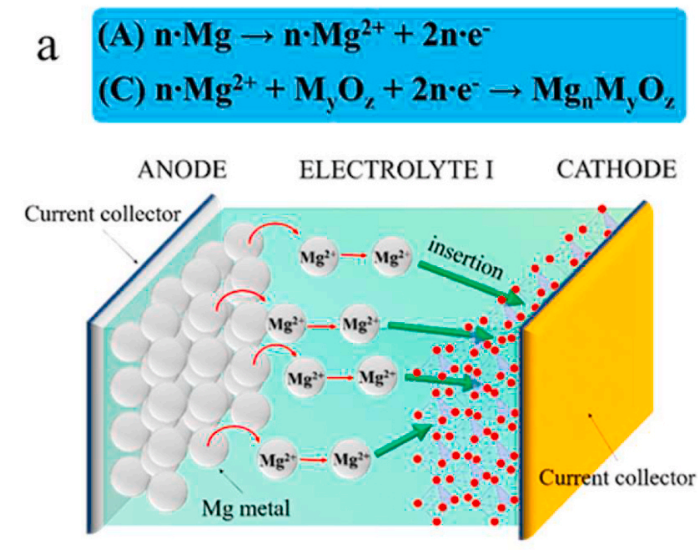

\section{Species I electrolytes}

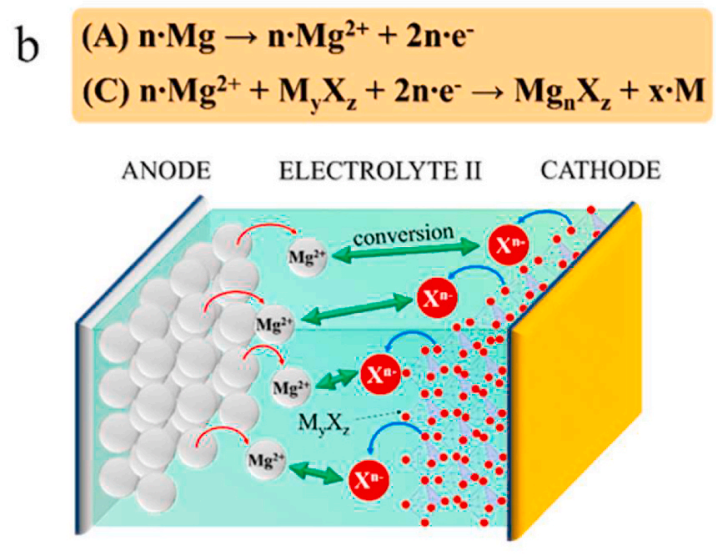

\section{Species II electrolytes}

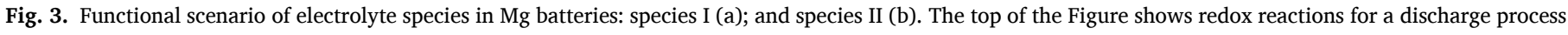
at both the anode (A) and the cathode (C) electrode. 
(stripping) and electrodeposition (plating) to the recrystallization processes of the metal electrodes into the different crystal forms. For a successful implementation of batteries based on the metal electrodes, we need metal anodes with a high reversibility in stripping and plating processes endowed with a Coulombic efficiency (CE) higher than $99.5 \%$. Even such a high efficiency correspond to almost 40 at.\% loss of metal after 100 cycles. Irreversibility of plating process is typically accompanied with a formation of new interfaces that are not thermodynamically stable in electrolytes. Required passivation consumes solvent(s) and salts or additives from electrolyte, leading to increased polarization and finally cell dry out.

Magnesium has low electronegativity and is a very reactive metal, whose surface rapidly passivates in contact with reducible species such as water, oxygen or electrolyte [33]. Unlike the formation of the solid electrolyte interphase on the lithium metal, many reports assume that passivation layers on the metallic magnesium have low ionic conductivity for magnesium cations. For instance use of fluoride based electrolytes, owing to their reactivity towards magnesium metal anode, yield on its surface an insulating and compact solid electrolyte interface (SEI) which reduces the $\mathrm{Mg}^{2+}$ ion conductivity and the Coulombic efficiency of the entire cell $[61,62]$. Such passivation can significantly impede the process of stripping and even more process of plating and create pits during stripping process and non-homogenous magnesium plating. Early generation of nucleophilic electrolytes $[15,20]$ in ether based electrolytes are keeping magnesium surface at least partially active (non-passivated). Additional energy needed for desolvatation impedes the plating process and calls for better understanding of the processes occurring in a double layer between metallic magnesium anode and electrolyte.

Overall, different parameters have influence on the electrochemical properties of magnesium metal electrode, among them one with the highest importance is related to electrolyte (see Table 1), its chemical properties, purity and concentration of salt(s). Besides, quality of magnesium metal (presence of dopants and native surface layer), current density, separator and cross communication with cathode are of paramount importance for evaluation of different $\mathrm{Mg}$ foils in various electrolytes/cathode materials combinations.

As earlier emphasized, CE of magnesium stripping and plating is a very crucial parameter, which can provide a clear value of the proposed improvements on the level of the cell components. This parameter cannot be simply evaluated from non-accurate electrochemical characterization techniques. Quite often, CE is extracted out from cyclic voltammetry measured at very high scan rates. Such measurements indeed show overpotential on the working electrode and provide first insight into the electrochemical mechanism but fail in accumulation of all chemical and electrochemical irreversible losses. For the evaluation of $\mathrm{CE}$, much more accurate measurements of stripping and plating need to be performed in three electrodes cells with a reliable reference electrode and with a working electrode containing electrodeposited magnesium which quantity is double or triple of the one that is removed during galvanostatic stripping. As counter electrode, pure magnesium metal foil can be used. Additional important parameters in such experiment are areal capacity and current density normalized per surface area of the working electrode. It is highly recommended to apply conditions that lead to the practical areal capacities (i.e. at least $1-2 \mathrm{mAh} \mathrm{cm}^{-2}$ ). Such realistic electrochemical tests will provide a good approximation of $\mathrm{CE}$, although cross communication with cathode is not considered. Additionally a post mortem analysis of working electrode is required to monitor morphological changes. Plating of metals can be accompanied with the formation of dendrites or non-uniform deposits, which can grow through the separator and create short circuit. Here, difference between magnesium and lithium is very important since melting point and hardness of magnesium metal is much higher compared to lithium metal and even some "soft" short circuits can create extensive damage to the cell.

Magnesium was considered for a long time as a metal whose plating is homogenous without formation of any dendritic form. Recently some authors pointed out the potential hazards related with a formation of dendritic forms or uneven deposits with a needle like structure on magnesium metal [76-78]. Homogenous plating of magnesium was explained by Jäckle et al. [79] who suggested that barriers of terrace surface diffusion and interlayer surface diffusion could be a descriptor of metallic deposition morphologies. Following this work, Kopac Lautar et al. [80] examined all possible surfaces in the magnesium metal crystal and they showed that the energetically most favorable surface [0001] supports homogenous plating while migration barriers on some other crystal planes are more in favor for non-homogenous plating. Considering high current density we can expect that also other crystal planes would be energetically favorable, leading to the formation of non-uniform magnesium deposits or even dendrites [76-78]. Moreover, highly active surfaces might be more exposed to passivation and can become blocking, thus promoting plating on energetically less favorable crystal planes. Formation of dendritic forms was observed in the study of Ding et al. [76] where different glyme solvents were used to prepare electrolyte with $\mathrm{Mg}(\mathrm{TFSI})_{2}$, a salt known as a highly passivating salt and very rarely used alone (Fig. 4a). Results show formation of non-uniform deposits which grow through the separator and cause short circuit in the $\mathrm{Mg} / / \mathrm{Mg}$ symmetrical cell. Dendritic growth on $\mathrm{Mg}$ ribbon has been observed by Davidson et al. [77] who cycled symmetrical cell in a Grignard electrolyte and with a current density close to the one requested for commercial application (Fig. $4 \mathrm{~b}$ and c). In agreement with that, Bitenc et al. [78] showed post-mortem SEM images of Mg anode after 500 cycles with a clear image of needle like $\mathrm{Mg}$ particles, which were plated on the magnesium anode (Fig. 4d).

Similar as migration barriers on the crystal planes can influence formation of non-uniform magnesium plating, ionic conductivity and transference number (discussed in previous section) for magnesium cation or for magnesium complex are also very crucial for homogenous distribution of ions and with that homogenous plating of magnesium metal.

\subsection{Alloys: from bulky electrode to surface protection?}

Some elements from block $p$ are known to electrochemically react with magnesium ions to form an alloy. This has been firstly reported by Toyota especially with sputtered electrode of bismuth or antimony or with nanosized tin particles [81,82]. Later on, the electrochemical behavior of lead, gallium and indium have been experimentally demonstrated [83-85]. Recently, Aurbach and coworkers provided an extensive overview of the alloy anode materials for RMBs [9]. In this section, the main features of these electrodes are briefly overviewed. The electrochemical reaction mainly proceeds through a flat alloying plateau at very low voltages (from $\sim 0.1$ for In and $\mathrm{Pb}$ to $\sim 0.4 \mathrm{~V}$ vs vs. $\mathrm{Mg} / \mathrm{Mg}^{2+}$ for $\mathrm{Sb}$ ), and X-ray diffraction revealed the biphasic transformation leading to crystalline alloy during discharge process. The corresponding gravimetric and volumetric capacities related to the electrochemical alloying are high (theoretically up to $900 \mathrm{mAh}^{-1}(\mathrm{Sn})$ and $6570 \mathrm{mAh} \mathrm{cm}^{-3}(\mathrm{Sn})$ for the formation of $\mathrm{Mg}_{2} \mathrm{Sn}$ ). Synergistic effects have been expected by combining multiple elements such as Bi-Sb (solid solution), Bi-Sn (composite), or intermetallic compositions of the type InBi, SnSb or InSb [86, 87, 88, 89, 90, 91, 92,93]. Like alloying-type electrode materials in lithium-ion batteries, the volumetric changes modulated by the alloying and de-alloying process could hamper the long-term cycling of the electrode. However, with a good electrode formulation, high reversible cycling has been demonstrated especially with Bi-based electrodes [94,95] (Fig. 5a).

Taking all together, these elements - and their corresponding alloys could be considered as possible negative electrode material in RMB, although their application is debated in the research community [4]. The calculation method here described allowed us to compare the practical energy densities of full cells with either $\mathrm{Mg}$ metal or $\mathrm{Mg}_{2} \mathrm{Sn}$ anodes, as we consider the latter as the most suitable option among all 


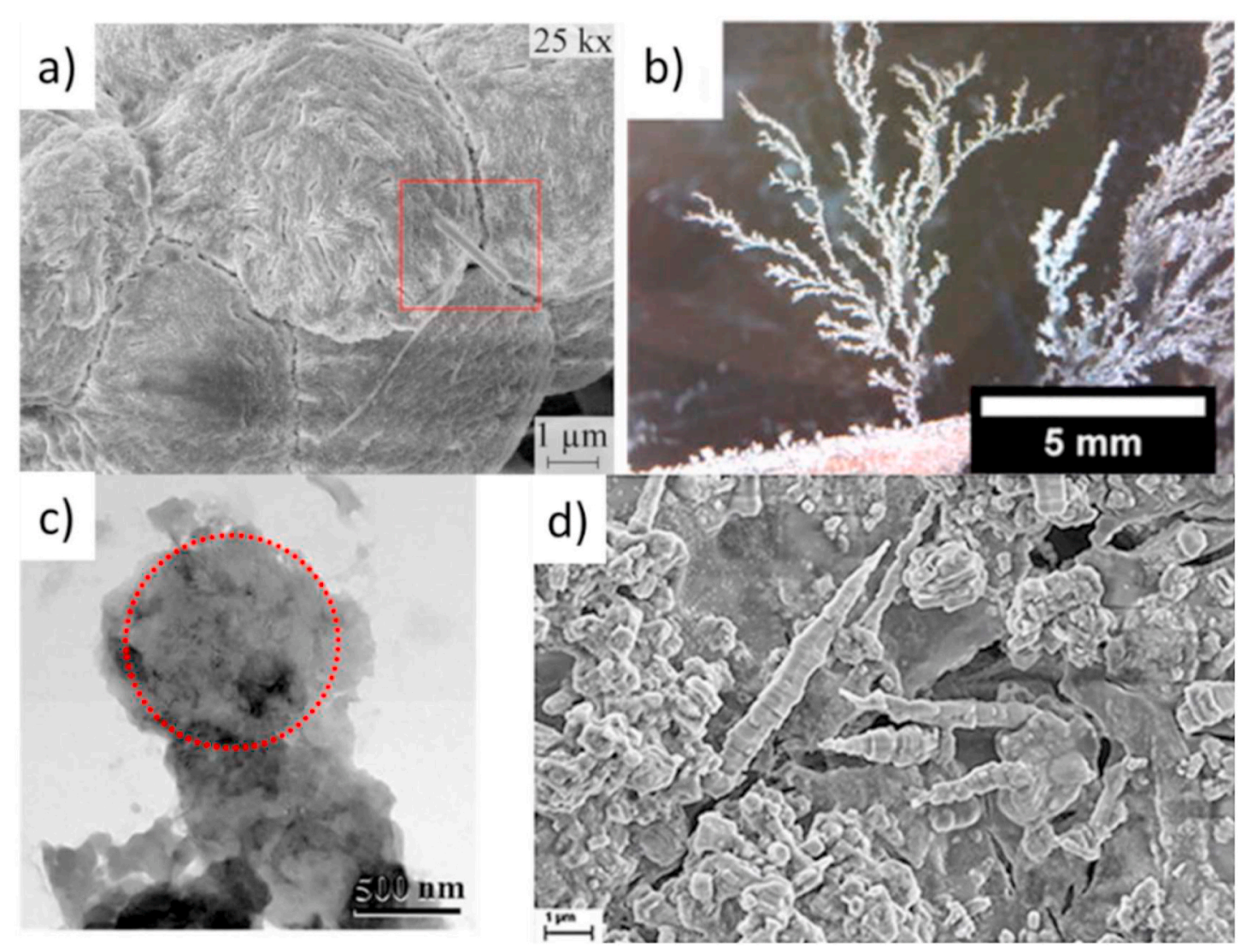

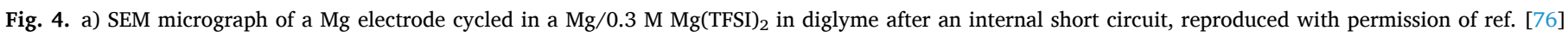

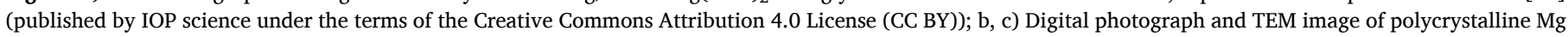

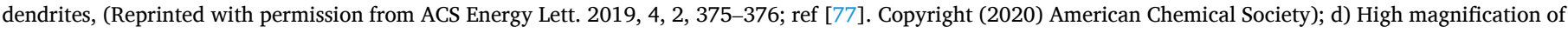

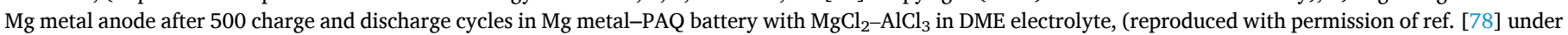
Creative Commons CC-BY license).

known alloys for reaching interesting performance. At a cell level, if considering similar positive electrode materials, energy densities with an alloy electrode will be logically lower that with a magnesium metal one (Fig. 1a).

Nevertheless, one important factor to consider is that alloy electrodes might be easier to produce than magnesium metal electrodes. Indeed, to take full advantage of $\mathrm{Mg}$ metal capacity, $\mathrm{Mg}$ foil with thickness of 3.9 $\mu \mathrm{m}$ needs to be manufactured to get a surface capacity of $1 \mathrm{mAh} \mathrm{cm}{ }^{-2}$, even when considering a $50 \% \mathrm{Mg}$ excess (Fig. S3). This may prove difficult and requires implementing evaporation methods to produce high purity and thin magnesium foils. Ultra-high purity atmosphere during assembling with no traces of oxygen and water is also mandatory to avoid passivation of the magnesium foil, implying burdensome handling protocols. Moving from magnesium foil to magnesium powder appears as a good alternative but its limitation is safety risk of magnesium powder handling and need for current collector. On the contrary, alloys can be synthetized in the form of powder by ball-milling or high temperature reactions, two methods that can be easily integrated in the battery industry. Consequently, the powders can be processed in the form of slurries and final composite electrodes, similarly to the existing procedures in the Li-ion battery industry. Alloys may also offer a safer handling, due to their lower reactivity with air, yet to be fully demonstrated.

It is also important to underline that alloys are certainly less surface sensitive than magnesium metal and that choosing magnesium metal restricts the electrolyte's choice to only few particular compositions. As it is here discussed in details in the "electrolyte" section, magnesium seems so far highly compatible with IL based- or Grignard-like electrolytes, which despite their promising cyclability and current density, up to today present a reasonable electrochemical potential window (EPW), yet lower than ca. $3 \mathrm{~V}$ (see Table 1). Alloys offer the possibility to extend this EPW in species I and II electrolytes, and likely to promote efficient operation in a full cell of other electrolytes of species I based on classical solvents (carbonates, nitriles). Indeed, from our knowledge, only few works are so far reported combining in a full cell alloy anodes $\left(\mathrm{Mg}_{3} \mathrm{Bi}_{2}\right.$ and $\mathrm{Mg}_{2} \mathrm{Sn}$ ) with classical $\mathrm{Mg}(\mathrm{TFSI})_{2}$-based electrolytes with acetonitrile or various other glymes [96-99] (Fig. 5b and c). However, alloying-type electrodes with $p$-block element are known to exhibit high cycling performance in lithium-ion or sodium-ion batteries with carbonate-based electrolyte [100-102]. Taking into consideration that the chemistry of the magnesium is completely different from that of alkaline elements, we are convinced that it is a great challenge today to explore new horizons by combining $\mathrm{Mg}_{x} \mathrm{M}$ alloys with species I or II electrolytes compatible with the cathode chemistries, thus opening the door for higher energy density cell chemistries.

Apart from considering alloys as bulky negative electrodes, they might be of interest for protecting the $\mathrm{Mg}$ surface from the dendritic growth. Indeed, magnesium electrochemical plating could be, in some cases, especially when combined with electrolytes of species I, characterized by dendritic growth as it has been shown in the section describing magnesium metal electrodes (Fig. 4). Thus, when new combinations [electrolytes of species I]-[cathode materials] are explored for the development of $\mathrm{Mg}$ metal batteries it is also of crucial importance to focus the attention on the best way to protect the surface of magnesium. An interesting approach is to create on the electrode surface a thin layer of alloying-type material relatively inert and non-reactive with most electrolyte components. Research groups of Nazar and Archer were among the first to investigate a facile and tunable methodology to 
a)

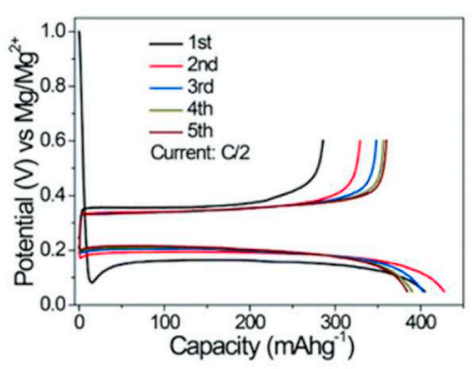

d)

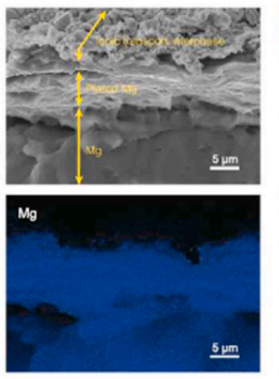

b)

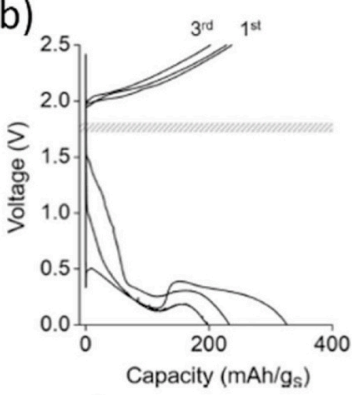

e)
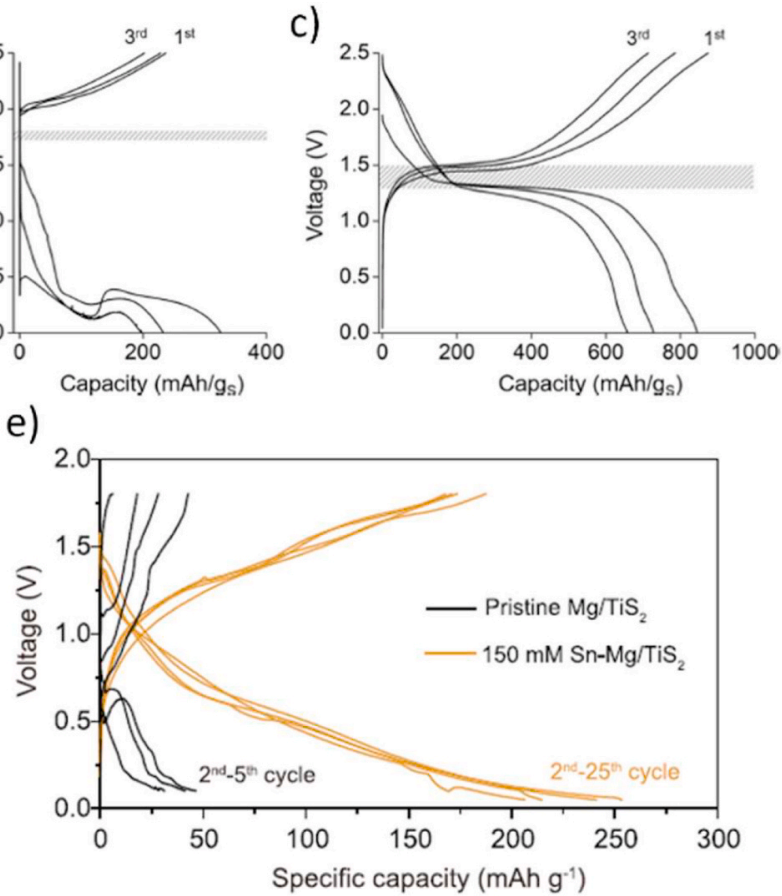

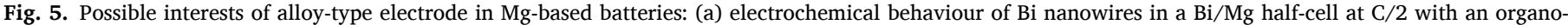

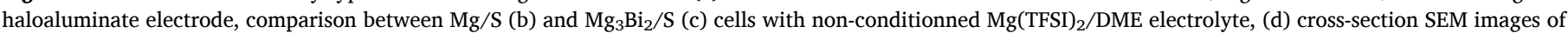

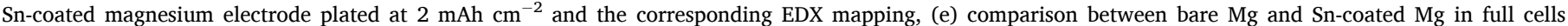

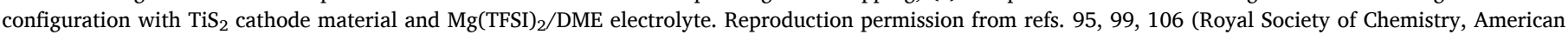
Chemical Society and Oxford University Press, respectively).

efficiently coat alloy on the surface of lithium and sodium electrodes by reducing $p$-block elements (In, $\mathrm{Sn}, \mathrm{Sb}, \mathrm{Bi}, \mathrm{As}$ ). This could be achieved by simply dropping metallic salt solution on the electrode surface of by completely immersing it, the instant salt reduction being driven by the lower redox potential of the alkali metal [103-105]. In most cases, the reaction further proceeds with an alloying step. Thanks to this in situ generated layer, the composite anode exhibits accelerated charge transfer kinetics and prolonged plating/stripping and operando microscopy reveals that the dendrite formation is clearly reduced. It is consequently reasonable to assume similar results on magnesium electrode. Very recently, Xia and Luo reported the first alloy coating attempts by dropping a $\mathrm{SnCl}_{2} / \mathrm{DME}$ solution onto magnesium surface [106]. A $2 \mu \mathrm{m}$ thick composite layer comprising Sn, $\mathrm{Mg}_{2} \mathrm{Sn}$, along with chlorides could be generated. The as-coated anode shows fast ionic transport at the interphase with a simple $\mathrm{Mg}(\mathrm{TFSI})_{2} / \mathrm{DME}$ electrolyte and extended cycling life has been achieved with $\mathrm{TiS}_{2}$ model cathode (Fig. 5d and e). This proof-of-concept poses the basis to a systematic benchmarking of the alloy-type coating that can be generated on the magnesium surface to determine their efficiency for avoiding any potential formation of dendrites or non-even deposits.

\section{Cathode materials}

\subsection{Insertion cathode materials}

Most studies on $\mathrm{Mg}$ batteries focus on combining $\mathrm{Mg}$ metal with inorganic cathodes based on transition metal redox centers. As of today, inorganic oxide, polyanionic and sulfide compounds are the main attention of the community but they all present their pros and cons that we will briefly define herein. The research on inorganic cathodes for magnesium batteries is sometimes quite perplexing as the lack of highly oxidative stable $\mathrm{Mg}$ electrolytes prevents evaluation of $\mathrm{Mg}$ insertion reactions at high voltages. On the other hand, use of electrolytes with high oxidative stability so far requires application of reference electrode or flooded cell with large reservoir of $\mathrm{Mg}^{2+}$ ions. Presence of different anions in electrolytes have high impact on coordination and consequently on desolvatation during insertion reaction at the electrolyte/ inorganic material interface. Indeed, the choice of the electrolyte of species I or II trigger the electrochemical mechanisms of the electrodes modulating differently their operation. Another of the most critical hurdles in inorganic compounds is the strong electrostatic interactions between $\mathrm{Mg}^{2+}$ and the host lattice, strongly restraining the diffusion of $\mathrm{Mg}^{2+}$ ions in the solid.

Research on cathode materials for $\mathrm{Mg}$ insertion was accelerated by the seminal work of Aurbach and al. with a prototype full $\mathrm{Mg}$ cell based on the Chevrel phase $\mathrm{Mo}_{6} \mathrm{~S}_{8}$ [20] and opened a large avenue of research on chalcogenides. These structures are very promising due to the weak electrostatic interactions between $\mathrm{Mg}^{2+}$ ions and the sulfide/selenide-based anion framework. The low operating voltage $(\sim 1.1 \mathrm{~V})$ and low specific capacity $\left(\sim 100 \mathrm{mAh}^{-1}\right)$ of $\mathrm{Mo}_{6} \mathrm{~S}_{8}$, connected with incomplete de-insertion of $\mathrm{Mg}$ ions caused by the trapping of partial charges at room temperature are limiting factor for commercial application of the given technology. Substituting sulfur by selenium allows for a $100 \%$ capacity usage [107] but at the expense of the specific capacity value. Voltage and capacity values are too modest to obtain energy densities competitive with Li-ion batteries but Chevrel structures remain as the benchmark electrodes for $\mathrm{Mg}$ batteries as they offer remarkable kinetics and good reversibility. Apart from Chevrel phases, some materials of interest are titanium sulfides with either layered $\left(\mathrm{TiS}_{2}\right.$ $[108,109])$ or spinel $\left(\mathrm{Ti}_{2} \mathrm{~S}_{4}\right.$ [110]) structures. While they offer good reversibility and improvement in capacity and voltage compared to Chevrel phases, the working voltage is still too low. Other chalcogenides such as $\mathrm{MoS}_{2}$ [111], $\mathrm{TiSe}_{2}$ [112] or WSe $\mathrm{W}_{2}$ [113] have also been evaluated. Overall transition metal chalcogenides in combination with metallic magnesium or magnesium alloys possess low energy density and the strategy of further development should focus on transition metal sulfides or selenides with cationic and anionic redox center. That was recently proposed by the group of Zhao-Karger and Fichtner by using 
transition metal polysulfide $\mathrm{VS}_{4}$ coupled with rGO (Fig. 6). Capacities close to $300 \mathrm{mAh} \mathrm{g}^{-1}$ at $100 \mathrm{~mA} \mathrm{~g}^{-1}$ have been obtained at an operating voltage around $1.25 \mathrm{~V}$ [114]. While the working voltage of this model electrode is still low, this study opens the way to the promising concept of anionic redox in the field of $\mathrm{Mg}$ batteries.

Ionicity of transition metal oxygen bonds is typically higher compared to ionicity with sulfur bonds in similar crystallographic coordination and that leads to the increase of the working potential [115]. Common transition metal oxide compounds have thus been thoroughly studied [116-126] as materials for $3 \mathrm{~V}$ magnesium batteries and recent review papers well summarize state of the art [4,127].

Among all oxides, most works focus on the different manganese compounds and vanadium oxides as attractive candidates for magnesium insertion mainly due to possible multielectron reaction and tunnel structures, which can serve as host sites for magnesium. Attractiveness of manganese oxides lies also in the high theoretical energy density when combined with pure magnesium foil or even with magnesium alloys (see Fig. 1). Namely, manganese oxides can be considered as a $3 \mathrm{~V}$ cathode material with at least $150 \mathrm{mAh} \mathrm{g}^{-1}$ specific capacity. Unfortunately, most of reports show serious degradation during first magnesium insertion and de-insertion, due to the irreversible formation of $\mathrm{MgO}$ $[128,129]$. Application of layered $\delta-\mathrm{MnO}_{2}$ (birnessite) typically leads to more stable cycling with capacities up to $230 \mathrm{mAh} \mathrm{g}^{-1}$ and operating voltages from $2.17 \mathrm{~V}$ to $\sim 3.0 \mathrm{~V}[124,126,130,131]$. Reversible change of oxidation state from trivalent to tetravalent manganese was determined by XANES and XPS [132] and structural stability was checked with XRD and HRTEM. It has to be mentioned that water is typically present between layers in birnessite structure and its role in the charge compensation is not clear up to date. $\lambda-\mathrm{MnO}_{2}$ represents another candidate for $\mathrm{Mg}$ insertion with a possible magnesium occupancy at tetrahedral sites. In theory, it should deliver more than $300 \mathrm{mAh} \mathrm{g}^{-1}$ capacity at $2.9 \mathrm{~V}$, which was not yet demonstrated, most likely due to poor $\mathrm{Mg}^{2+}$ mobility caused by high migration barriers [130]. The best electrochemical performance has been obtained in flooded cell using aqueous solution of $\mathrm{Mg}\left(\mathrm{NO}_{3}\right)_{2}$ [133], while measurements in organic electrolytes show much more sluggish electrochemical characteristics probably connected with low oxidative stability of electrolytes and high energy barrier for desolvatation of magnesium cation.

Other interesting oxide structures for magnesium insertion are based on the $\mathrm{V}_{2} \mathrm{O}_{5}$ composition [117-119] and $\mathrm{MoO}_{3}$ [119]. Different studies showed that orthorhombic $\mathrm{V}_{2} \mathrm{O}_{5}$ can accommodate up to half a mole of $\mathrm{Mg}$ per formula unit, which is significantly lower compared to capacities obtained in lithium system. Higher capacities can be obtained in water based electrolytes or in systems containing water primarily due to expanded space between interlayers, but also due to the presence of shielding water molecules in the host structure, reducing the charge density of the $\mathrm{Mg}^{2+}$ ions $[118,120]$.

This presence of water was largely applied to vanadium oxide either by addition of water in the electrolyte or by the formation of $\mathrm{V}_{2} \mathrm{O}_{5}$ xerogel [134]. With an electrolyte of $1 \mathrm{M} \mathrm{Mg(TFSI})_{2}$ in diglyme containing 2600 ppm of $\mathrm{H}_{2} \mathrm{O}$, Sa et al. obtained performances as high as 250 mAh $\mathrm{g}^{-1}$ while only $60 \mathrm{mAh} \mathrm{g}^{-1}$ were obtained in the "dry" electrolyte [118]. Water molecules therefore seem to improve performance, however it is not clear yet if the capacity observed is solely explained by the insertion of $\mathrm{Mg}^{2+}$ or if a reversible insertion of protons into the $\mathrm{V}_{2} \mathrm{O}_{5}$ material exists. Moreover, presence of water in the electrolyte precludes the use of $\mathrm{Mg}$ metal and renders the benefits of these cathodes highly questionable. Recently, a novel strategy was applied by protecting an electroactive $\mathrm{VO}_{\mathrm{x}}$ "core" nanoparticle by a GO "shell" in a "chrysalis"-like architecture [75]. This cathode, in combination with a Mg metal foil anode and an oxygen-free electrolyte of species II, allowed to cycle a full cell battery at very high current rates (i.e., $1000 \mathrm{~mA} \mathrm{~g}^{-1}$ ) achieving a power of $1.7 \mathrm{~W} \mathrm{~g}^{-1}$ and a cathodic specific capacity of $72 \mathrm{mAh} \mathrm{g}^{-1}$ [75].

Few classes of other oxides, supposed to show structural stability and 3D mobility, have been evaluated such as spinel or polyanionic compounds [123-126], including NASICON. Yet, these structures again suffer from the sluggish diffusion of $\mathrm{Mg}^{2+}$ in their lattice and quite low performance. One original approach to increase the capacity of oxide materials is the creation of cationic vacancies, acting as intercalation sites and favoring $\mathrm{Mg}^{2+}$ insertion. Using an aliovalent doping, this

\section{a)}

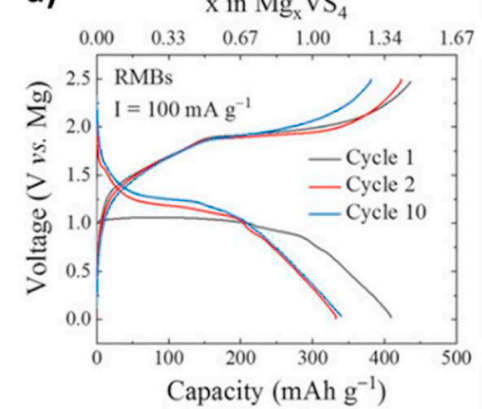

b)

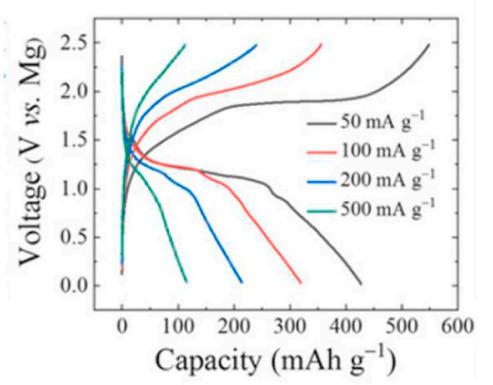

c)

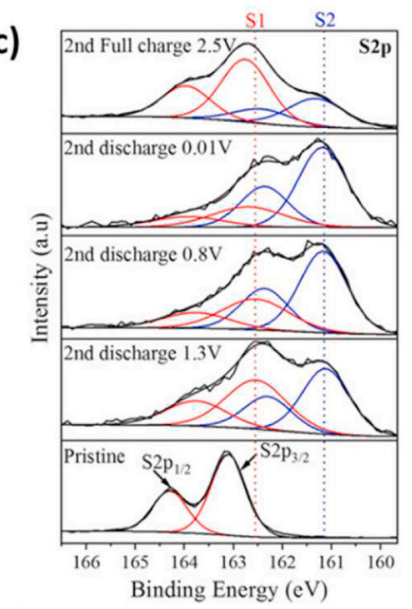

e)

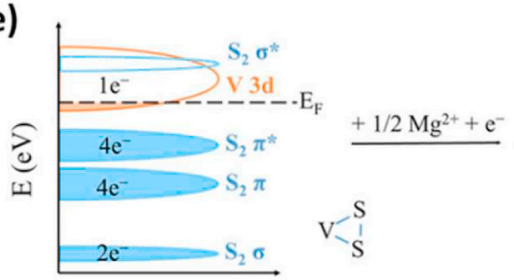

d)
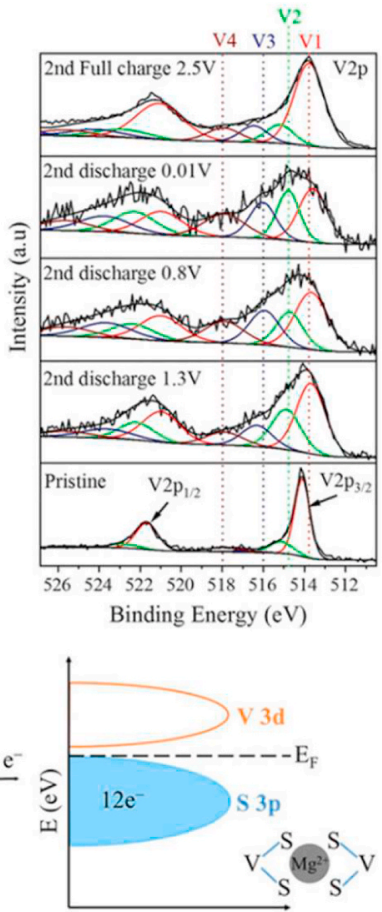

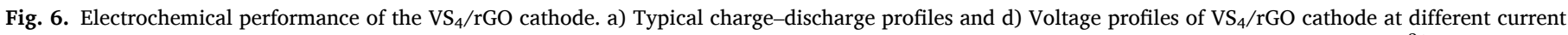

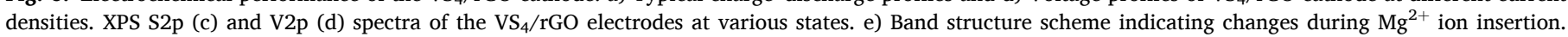

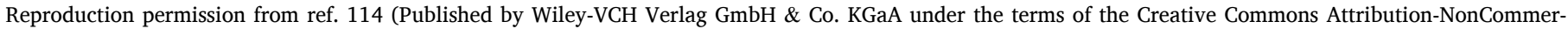
cial License). 
strategy significantly increased the capacity of $\mathrm{TiO}_{2}$ [135], but needs to be applied generally to other oxide compounds.

Most of papers report that the common approach used in lithium ion batteries (LiBs) can not be simply transferred to the Mg technology. As already mentioned this is due to problems related to: (a) insertion kinetics influenced by the energy required for desolvatation; (b) sluggish diffusion at moderate and high rates [130,131]; and (c) different insertion mechanism due to the exchange of more than one electron per transition metal. The latter often favors undesired conversion mechanisms over intercalation processes. This is rationalized by the thermodynamic driving force towards the formation of $\mathrm{MgO}$ [130]. Thus it is highly important that studies in the future address all three points by careful studying how different electrolytes influence insertion kinetics and possible co-insertion of different species that might influence diffusion. At the same time operando or in situ characterization needs to be accompanied with careful electrochemical characterization for clarification of the mechanisms and to identify rigorously the insertion and conversion processes and to evaluate unequivocally the performance of the positive electrode.

To summarize, future search for novel cathode materials or composite electrodes suitable as magnesium insertion hosts should be accompanied with careful decoupling of different phenomena related to magnesium insertion. Electrochemical stability window of electrolytes, insertion/desolvatation kinetics, diffusion of magnesium within the solid structure and structural stability are among the most important, but also porosity of the composite electrode (ionic pathways), type of electron conductive additive, binder and finally loading can significantly impact evaluation of different cathodes for magnesium batteries. With that, a proper selection of electrolytes with a high oxidation stability and at the same time compatibility with magnesium metal or alloys is a prerequisite condition. That does not exclude use of electrolytes with low compatibility with negative electrode as long as this is used for mechanistic studies and not for studies where material is proposed as an active component for $\mathrm{Mg}$ batteries. However, the use of water containing electrolytes or in general of electrolytes based on oxygenated matrices without protection on the magnesium metal anode has limited practical meaning. Finally, as already mentioned, materials loading and composite electrode structure should be aligned with needs for commercial applications. Currently, most of studies use very low areal loadings of active material.

\subsection{Conversion cathode materials}

Sluggish insertion kinetics and slow diffusion of divalent cation inside the crystalline structure can be mitigated with conversion reactions. Different conversion materials have been studied as potential cathodes for magnesium batteries including sulfur and selenium, iodine and bromides, and some transition metal sulfides and selenides among others. Specific nature of conversion of the electrochemical reactions is related to the high polarization, possible dissolution of intermediate products and loss of ionic and electronic contacts between current collector/separator and active material. Additionally, dissolved intermediate reduction products can migrate/diffuse from cathode to anode side causing infinite shuttle or deposits on the magnesium metal. This is particularly valid for the magnesium-sulfur system, which is considered highly attractive from the point of view of the material availability and performance. Major drawback of conversion reactions are low operating voltages, which fit well into the stability window of already-known electrolytes. The electrophilic chemical character of some cathode materials implies that most of electrolytes from the early stage development simply could not be used due to non-compatibility between nucleophilic electrolytes and active material. That explains well relatively late first report on the $\mathrm{Mg}-\mathrm{S}$ battery system proposed by Muldoon et al., in 2011 [22]. Use of 3:1 mixture of $\mathrm{HMDSMgCl}$ to $\mathrm{AlCl}_{3}$, recrystallized [Mg2 $(\mu-\mathrm{Cl})_{3} \cdot 6 \mathrm{THF}$ [ $\mathrm{HMDSAlCl}_{3}$ ] in THF enabled the first reversible cycling of a Mg-S system. Only two cycles were shown with high polarization and low cycling efficiency. Reversibility of electrochemical reactions was confirmed by use of XPS. The same characterization technique was used in the follow up work by Zhao-Karger who concluded that the end discharge product is not $\mathrm{MgS}$, but $\mathrm{MgS}_{2}$. Using operando mode sulfur K-edge XANES characterization, Robba et al. [136] determined that the reduction mechanism is a classical sulfur reduction, which proceeds through formation of long and short chain polysulfides that ends with the final reduced phase of MgS (Fig. 7). Different groups later confirmed formation of $\mathrm{MgS}$ as the most reduced final discharge product. Currently crystallographic structure of electrochemically prepared $\mathrm{MgS}$ phase is under debate, whether it crystallizes in orthorhombic [137] or tetrahedral structure [136]. Difference in the structure is not only interesting for scientific debates, but also from the point of view of volumetric expansion, which can significantly impacts integrity of the composite electrode. Namely, moving from orthorhombic to tetrahedral structure of $\mathrm{MgS}$ corresponds to almost 3 times larger expansion of material in case of tetrahedral structure. Formation of polysulfides, metal sulfide as the end discharge product, continuous expansion and contraction, passivation of metal anode with dissolved polysulfides are only few of typical processes known from Li-S batteries, which are also present in $\mathrm{Mg}-\mathrm{S}$ batteries. Thus, it is not surprising that two plateaus obtained during reduction of sulfur correspond to very similar reduction pathways; i.e. formation of long chain polysulfides at high voltage plateau, their reduction in the region between the two plateaus and final precipitation of $\mathrm{MgS}$ in the low voltage plateau. Mainstream in the development of $\mathrm{Mg}-\mathrm{S}$ batteries is continuous search for novel electrolytes, which can enable long-term cyclability under the lean electrolyte conditions that has not been achieved up to date. Different groups have tried to improve cyclability of $\mathrm{Mg}-\mathrm{S}$ battery using various strategies, from modification of the separator with carbon [138], increasing salt concentration [139], to the use of copper foil as current collector. The latter approach led to improved cycling stability through the formation of a single discharge plateau at $1.1 \mathrm{~V}$ vs. $\mathrm{Mg} / \mathrm{Mg}^{2+}$. Non-typical electrochemical response was first correlated to changes in electrolyte composition [140,141]. However, a careful analytical work revealed copper corrosion which influences the electrochemical reactions yielding a CuS active phase [142]. In this case corroded copper cations act as scavengers for polysulfides and enable long-term cyclability. Improvements in the $\mathrm{Mg}-\mathrm{S}$ cell cyclability have been obtained also by use of highly concentrated electrolytes where solubility of polysulfides is limited. The role of soluble polysulfides in $\mathrm{Mg}-\mathrm{S}$ batteries is not known yet. On one hand, solubility of sulfur and polysulfides leads to improved kinetics of sulfur conversion to sulfide, but on the other hand, soluble polysulfides can diffuse/migrate towards magnesium anode. Additionally, the presence of polysulfides in electrolyte can change physicochemical properties of electrolyte (viscosity, conductivity, solubility for salts, etc.) leading to fast capacity decay. Apart from the lack of fundamental understanding, more research efforts are needed in the design of engineered materials, which can support fast kinetics in the system with high electrolyte/sulfur ratio and composite electrode having high areal capacity. Although theoretical energy density for $\mathrm{Mg}-\mathrm{S}$ batteries is very high, practical cells that consider electrolyte/sulfur ratio and areal loading, lead to gravimetric energy density comparable to current Li-ion batteries, while volumetric energy density is much lower (Fig. 1).

Use of selenium instead of sulfur would lead to even lower energy densities and raises the question of sustainability of such battery system. Similarly, other conversion cathode materials, like before mentioned CuS or iodine lead to energy densities that are much easily achievable in other battery systems which are in the commercial use or close to the commercialization.

Iodine-based cathodes, which are very appealing due to their low cost and high specific capacity, exploit the reversible $\mathrm{I}^{3-}+2 \mathrm{e}^{-} \rightarrow 3 \mathrm{I}^{-}$ $\left(\mathrm{E}_{0}=0.536 \mathrm{~V}\right)$ reaction. This reaction, coupled with the magnesium electrooxidation, gives rise to a battery working at a theoretical potential of $2.9 \mathrm{~V}$ [32]. Latter report showed lower operating voltage of $2.2 \mathrm{~V}$ 

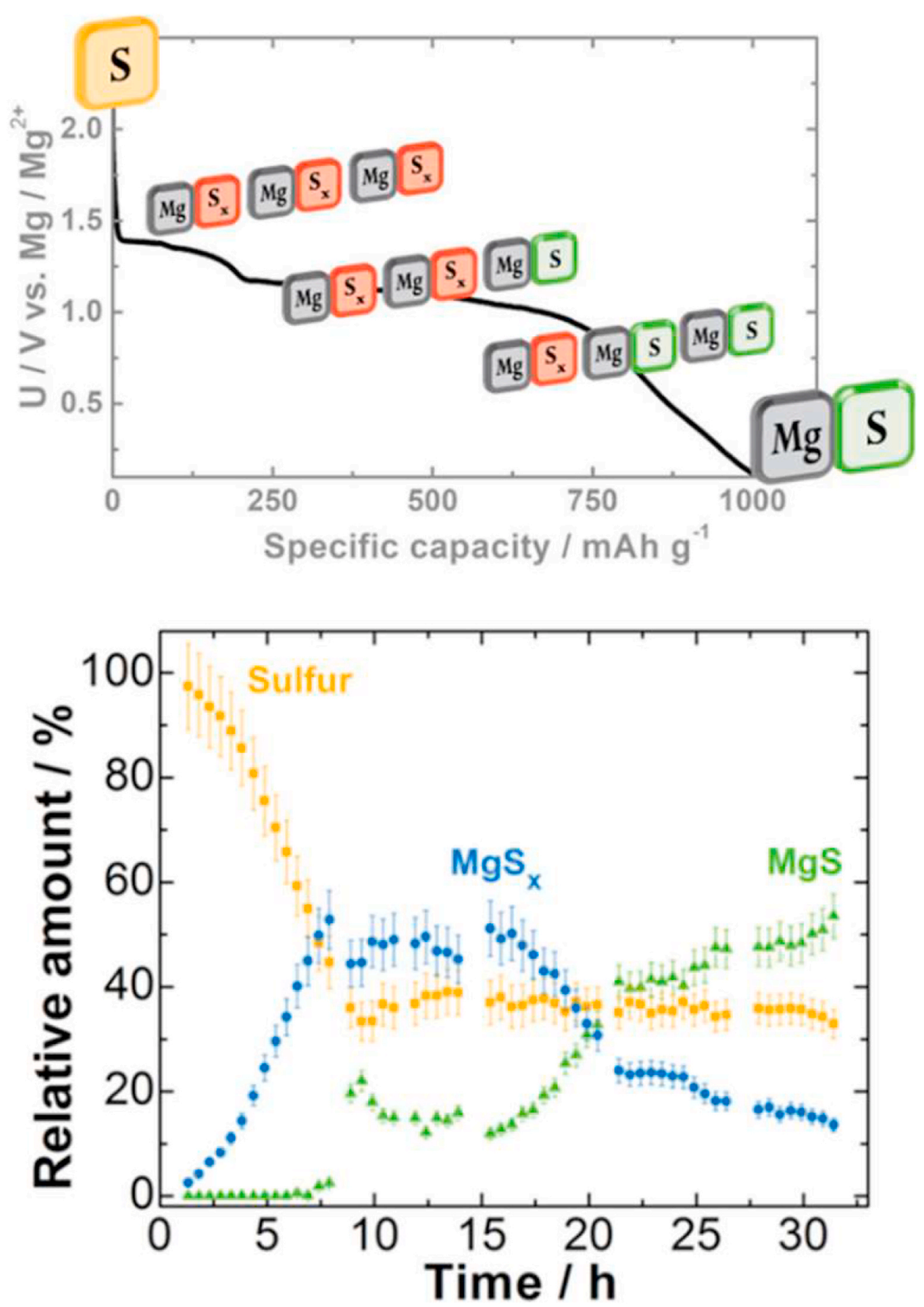

Fig. 7. Discharge profile of Mg-S battery and sulfur species as derived out from RIXS and XANES measurements, Reprinted with permission from Ref. [136]) (Chem. Mater. 2017, 29, 21, 9555-9564). Copyright (2020) American Chemical Society.

for $\mathrm{I}_{2} / \mathrm{I}_{3}^{-}$redox pair and $1.8 \mathrm{~V}$ for $\mathrm{I}_{3}^{-} / \mathrm{I}^{-}$redox pair [143]. The use of iodide-based electrolytes would easily unlock the possibility of the realization of a $\mathrm{Mg} / \mathrm{I}_{2}$ rechargeable battery.

\subsection{Coordination cathode materials}

Redox active organic materials represent a group of active materials that can successfully circumvent drawbacks encountered with the high voltage insertion cathodes. Typically, redox active organic materials have open structures enabling easier diffusion of electroactive species, which are used for charge compensation. Two types of redox active organic materials exist, $\mathrm{n}$-type that coordinates cations and p-type that coordinates anions, with addition of bipolar materials, which can coordinate both. N-type is much more realistic from the prospective of high-energy density $\mathrm{Mg}$ batteries since reservoir for cations is highly dense magnesium anode. Again, any practical application would require attractive properties like energy density and power density, which can be hampered by the low gravimetric density of organic active moieties, mainly in the form of polymers. In part, this can be compensated with excellent properties offered by magnesium metal anode. Considering cathode with a specific capacity of $350 \mathrm{mAh}^{-1}$, cells with a gravimetric energy density close to $300 \mathrm{Wh} \mathrm{kg}^{-1}$ and volumetric energy density up to $400 \mathrm{Wh} \mathrm{L}^{-1}$ can be foreseen after proper electrode engineering.

Low volumetric energy density, along with the potential dissolution 
of organics in the aprotic solvents are two major hurdles of Mg-organic rechargeable batteries. Reversible electrochemical nature of organic materials has been demonstrated for different battery systems and currently, redox active organic materials are one of the most promising candidates for rechargeable $\mathrm{Mg}$ batteries since this type of cathodes can provide long-term cyclability and high rates cycling due to their open structure that enables fast diffusion of electroactive species. Dissolution of organic active material has been mitigated mainly by synthesis of insoluble polymers from electroactive monomers, and penalty for this stabilization is the decrease of the specific capacity due to increase of molecular weight of redox active units. Other important advantages of $\mathrm{Mg}$ organic batteries are their sustainability and high environmental compatibility. Both redox active components in the Mg-organic battery are highly abundant in nature and redox active organics can be synthesized at much lower temperature compared to inorganic materials. Additionally, most of the redox potentials of active organic compounds
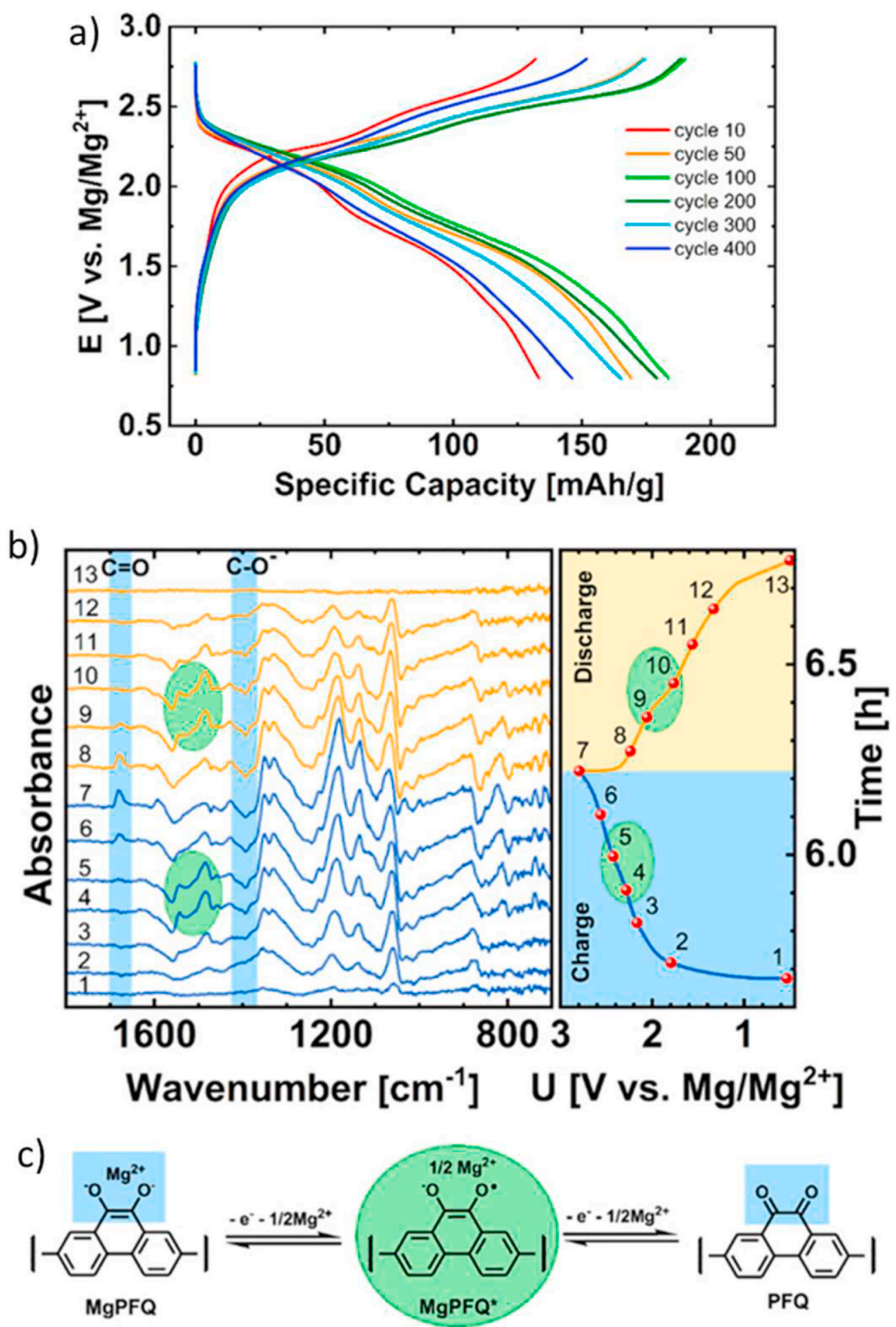

Fig. 8. Electrochemical cycling and electrochemical mechanism of poly(phenanthrene quinone)/reduced graphene oxide cathode (PFQ/rGO). a) Long-term cycling of $\mathrm{PFQ} / \mathrm{rGO}$ at $0.5 \mathrm{C}$ in $\mathrm{Mg}(\mathrm{TFSI})_{2}-2 \mathrm{MgCl}_{2}$ in DME electrolyte. b) Subtracted operando ATR-IR spectra of organic cathode displaying IR active changes during electrochemical cycle. c) Proposed electrochemical mechanism of PFQ/rGO cathode. Reproduced from reference 148 under open access CC BY 4.0 license. 
fit well within the electrochemical stability window of classical species I and II Mg electrolytes.

Quinone based monomers are particularly suitable as an active storage unit since most of recent reports [144-147[78]] provided highly attractive properties in terms of energy and power density as well as cyclability. Other reports showed applicability of imides and radical organic compounds [148-151], which in theory have less attractive properties in terms of energy density. First full cell behavior of $\mathrm{Mg}$ metal organic battery was published in 2015 using redox active organics based on poly(anthraquinonyl sulphide) (PAQS) and three different non-nucleophilic $\mathrm{Mg}$ electrolytes $\left(\mathrm{Mg}_{2} \mathrm{Cl}_{3}-\mathrm{HMDSAlCl}{ }_{3}\right.$ and $\mathrm{MgCl}_{2}-\mathrm{AlCl}_{3}$ in THF and $\mathrm{Mg}$ (TFSI $)_{2}-\mathrm{MgCl}_{2}$ in THF:DME electrolyte) [144], and since then different polymers showed excellent properties and long term cycling stability (Fig. 8). The reaction mechanism of organic cathode materials was investigated in a special cell developed for operando IR spectroscopy of organic cathode materials. With a combination of operando IR spectroscopy and DFT modelling Vizintin et al. [152] proposed a model showing how $\mathrm{Mg}^{2+}$ cation coordinate two quinone sites from two different monomer units. That required slightly different stretching of monomer units as in case of Li organic battery and that can be observed as slight upshift of carbonyl bond in IR spectra (Fig. 8b). Electrochemical activity of redox active organics partially depends on the type of electrolyte used in cells and on its accessibility of electrons to electrochemical active sites. The latter can be mitigated by using nanostructured organics or organics synthesized in the presence of carbon additives like carbon nanofibers, carbon nanotubes or graphene [147]. As mentioned, electrochemical characteristics depend also on type of electrolyte, where both salts and solvents play important roles $[78,145,148]$. It has been demonstrated that using the $\mathrm{Mg}(\mathrm{TFSI})_{2}$ salt can increase the capacity utilization of organic compounds, while use of $\mathrm{AlCl}_{3}$ can upshift the potential of redox active compounds [148,153]. Additionally, recent reports confirmed the presence of monovalent $\mathrm{MgX}^{+}$coordination cations where $\mathrm{X}$ is mainly the $\mathrm{Cl}^{-}$anion $[154,155]$. The presence and the role played in electrolytes by $\mathrm{MgCl}^{+}$ions, which are based on $\mathrm{Mg}-\mathrm{Cl}$ covalent bonds, was for the first time extensively studied in early 2002 [47,156-158]. These investigations demonstrated that its concentration depends on the salt density and on the permittivity of the electrolyte matrices. Given the hard acid nature of $\mathrm{Mg}^{2+}$ cation, the presence of such complexes is not surprising owing to the weakly coordinating organic groups and to the low permittivity of the electrolyte ( $\varepsilon$ is 8 and 4 for tetraglyme and 1,3-dioxolane, respectively).

Although redox active organics in form of different polymers show the best properties in terms of cycling and rate capability, there are still some important challenges that need to be addressed before their potential commercialization. Coordination of redox active sites with monovalent $\mathrm{MgX}^{+}$cation requires excess of electrolyte, which was not considered in our calculations (Fig. 1). New electrolytes with a weakly coordinated Mg cation are thus needed. Most of the work published in the literature shows results with cathodes having areal capacity below 1 $\mathrm{mAh} \mathrm{cm}^{-2}$ and a large excess of electrolyte. Such set-up can mask degradation of electrolyte and slows down the increase of electrolyte viscosity due to dissolution of polymer. At the same time excess of electrolyte can also accelerate dissolution of organic compounds and accelerate capacity fade. Finally, chemical vs. electrochemical ageing need to be carefully studied in the future, together with safety tests to foresee any pitfalls of this battery technology in the long-term operation.

\section{Conclusions}

Development of rechargeable magnesium batteries is still at the laboratory level with some attempts to prepare small prototype cells. Its chemistry is complicated, unexplored and totally different from that of other alkali metal systems used for the development of other types of secondary batteries. Thus in order to confirm calculations, which suggest energy density higher than $300 \mathrm{Wh} \mathrm{kg}^{-1}$ and $600 \mathrm{Wh} \mathrm{L}^{-1}$, a significant effort is required in order to explore this wonderful mine of electrochemical possibilities. That can likely provide interesting results with $3 \mathrm{~V}$ inorganic cathode material having specific capacity of $150 \mathrm{mAh}$ $\mathrm{g}^{-1}$, or with sulfur based cathode combined with metallic magnesium foil with $50 \%$ of excess. Neither oxide cathode with high performance, nor stable cycling of magnesium sulfur battery have been achieved so far. That calls for continuous research efforts on low technological reediness levels with a focus on different cell components and understanding interfaces and interphases. Use of magnesium alloys lowers energy density on the cell level, but due to better compatibility with different electrolytes and less sensitivity to oxidative atmosphere, alloys are still on the list of potential anodes for RMB. Recently, most of the research efforts are focused on the development of novel electrolyte formulations of both species I and II and on the discovery of novel cathode materials. In the last decade, several new electrolyte formulations mainly based on the development of novel weakly coordinating salts enabled use of different cathode materials. Unfortunately, few of newly proposed electrolytes can deliver close to $100 \%$ Coulombic efficiency during magnesium stripping and plating processes and their oxidative stability is in the most cases determined with the high scan cycling voltammetry. Additionally, with some rare exceptions, stripping and plating tests are performed at low current densities, not useful for the practical application. Recent reports on uneven, dendrite like, deposits during magnesium plating calls for more detailed morphological studies whenever new electrolytes or new materials/components are tested. Less or almost nothing is known about stability on interfaces, formation of possible passivation layers and energy needed for magnesium desolvatation.

Although RMB have many open questions, which need to be addressed before commercialization, recent progress in the development of electrolytes and cathode materials based on conversion or coordination mechanisms shows very promising directions that can pave a way to the future prototype cells. Meanwhile further efforts should also be devoted in the development of electrolytes (either liquid, polymer or solid state) which better reconcile the different electrochemical mechanisms which modulate the performance of anodic and cathodic interfaces. This will allow to obtain anode/electrolyte/cathode combinations appropriately exploiting the properties offered by the high voltage inorganic cathode materials, to obtain practical high performing RMBs.

\section{CRediT authorship contribution statement}

Robert Dominko: Conceptualization, Writing - review \& editing. Jan Bitenc: Writing - original draft. Romain Berthelot: Writing original draft. Magali Gauthier: Visualization, Writing - original draft. Gioele Pagot: Writing - original draft. Vito Di Noto: Writing - review \& editing.

\section{Declaration of competing interest}

The authors declare that they have no known competing financial interests or personal relationships that could have appeared to influence the work reported in this paper.

\section{Acknowledgement}

R. D. and J. B. would like to acknowledge financial support from Slovenian Research Agency under research project Z2-1864 and research program P2-0393 as well as long-term collaboration and financial support on the field of RMB with HONDA R\&D, Germany. M. G. acknowledges financial support from the Agence Nationale de la Recherche (ANR) of France under the contract ANR-16-CE05-0004. R. B. would like to acknowledge financial support from Agence Nationale de la Recherche (ANR) of France under research project ANR-10-LABX-7601 and ANR-19-CE05-0013. G.P and V.D.N. acknowledge financial support from the program "Budget Integrato per la Ricerca 
Interdipartimentale-BIRD 2018" of the University of Padova (protocol BIRD187913), the project TRUST (protocol 2017MCEEY4) of the Italian MIUR funded in the framework of "PRIN 2017" call, and ENI S.p.A., in the framework of two collaborative research projects (protocol 1157 of 22/04/2016 and OdL n. 4310294776 of 28/08/2018). V.D.N. thanks the University Carlos III of Madrid for the "Cátedras de Excelencia UC3MSantander" (Chair of Excellence UC3M-Santander).

\section{Appendix A. Supplementary data}

Supplementary data to this article can be found online at https://doi. org/10.1016/j.jpowsour.2020.229027.

\section{References}

[1] https://ec.europa.eu/energy/topics/technology-and-innovation/strategic-energy -technology-plan_en.

[2] S.S. Pathak, S.K. Mendon, M.D. Blanton, J.W. Rawlins, Magnesium-Based Sacrificial Anode Cathodic Protection Coatings (Mg-Rich Primers) for Aluminum Alloys Metals 2, Metals, 2012, pp. 353-376, https://doi.org/10.3390/ met2030353.

[3] H. Friedrich, S. Schumann, Research for a "new age of magnesium" in the automotive industry, J. Mater. Process. Technol. 117 (3) (2001) 276-281, https://doi.org/10.1016/S0924-0136(01)00780-4.

[4] P. Bonnick, J. Muldoon, A trip to oz and a peak behind the curtain of magnesium batteries, Adv. Funct. Mater. 30 (2020), 1910510, https://doi.org/10.1002/ adfm.201910510.

[5] A. Ponrouch, J. Bitenc, R. Dominko, N. Lindahl, P. Johansson, M.R. Palacin, Multivalent rechargeable batteries, Energy Storage Mater. 20 (2019) 253-262, https://doi.org/10.1016/j.ensm.2019.04.012.

[6] J. Bitenc, R. Dominko, Opportunities and Challenges in the Development of Cathode Materials for Rechargeable Mg Batteries, Front. Chem. 6 (2018), 634, https://doi.org/10.3389/fchem.2018.00634.

[7] Z. Guo, S. Zhao, T. Li, D. Su, S. Guo, G. Wang, Recent Advances in Rechargeable Magnesium-Based Batteries for High-Efficiency Energy Storage, Adv. Energy mater 10 (21) (2020), 1903591, https://doi.org/10.1002/aenm.201903591.

[8] R. Attias, M. Salama, B. Hirsch, Y. Goffer, D. Aurbach, Anode-Electrolyte Interfaces in Secondary Magnesium Batteries, Joule 3 (1) (2019) 27-52, https:// doi.org/10.1016/j.joule.2018.10.028.

[9] N. Jiazheng, Z. Zhonghua, D. Aurbach, Alloy Anode Materials for Rechargeable Mg Ion Batteries, Adv. Energy Mater. 10 (23) (2020), 2000697, https://doi.org/ 10.1002/aenm.202000697.

[10] P.W. Jaschin, Y. Gao, Y. Li, S.-H. Bo, A materials perspective on magnesium-ionbased solid-state electrolytes, J. Mater. Chem. A 8 (2020) 2875-2897, https:// doi.org/10.1039/C9TA11729F.

[11] Y. Zhan, W. Zhang, B. Lei, H. Liu, W. Li, Recent development of Mg ion solid electrolyte, Front. Chem. 8 (2020), 125, https://doi.org/10.3389/ fchem.2020.00125.

[12] D. Mazouzi, D. Reyter, M. Gauthier, P. Moreau, D. Guyomard, L. Roué, B. Lestriez, Very high surface capacity observed using Si negative electrodes embedded in copper foam as 3D current collectors, Adv. Energy Mater. 4 (8) (2014), 1301718, https://doi.org/10.1002/aenm.201301718.

[13] E.J. Berg, C. Villevieille, D. Streich, S. Trabesinger, P. Novák, Rechargeable batteries: grasping for the limits of chemistry, J. Electrochem. Soc. 162 (14) (2015) A2468-A2475, https://doi.org/10.1149/2.0081514jes.

[14] P. Jolibois, Comptes Rendus 155 (1912) 353-355.

[15] T.D. Gregory, R.J. Hoffman, R.C. Winterton, Nonaqueous Electrochemistry of Magnesium : Applications to Energy Storage, J. Electrochem. Soc. 137 (3) (1990) 775-780, https://doi.org/10.1149/1.2086553.

[16] V. Di Noto, M. Fauri, Batterie Primarie (Non Ricaricabili) e Secondarie (Ricaricabili) a Base di Elettroliti Polimerici Basati su Ioni Magnesio, 1999. PD99A000179.

[17] V. Di Noto, M. Fauri, Magnesium-based primary (non-rechargeable) and secondary (rechargeable) batteries, 2000. PCT/EP00/07221.

[18] V. Di Noto, S. Bresadola, New synthesis of a highly active $\delta-\mathrm{MgCl}_{2}$ for $\mathrm{MgCl}_{2}$ / $\mathrm{TiCl}_{4} / \mathrm{AlEt}_{3}$ catalytic systems, Macromol. Chem. Phys. 197 (11) (1996) 3827-3835, https://doi.org/10.1002/macp.1996.021971126.

[19] M. Vittadello, P.E. Stallworth, F.M. Alamgir, S. Suarez, S. Abbrent, C.M. Drain, V. Di Noto, S.G. Greenbaum, Polymeric $\delta-\mathrm{MgCl}_{2}$ nanoribbons, Inorg. Chim. Acta 359 (2006) 2513-2518, https://doi.org/10.1016/j.ica.2006.01.044.

[20] D. Aurbach, Z. Lu, A. Schechter, Y. Gofer, H. Gizbar, R. Turgeman, Y. Cohen, M. Moshkovich, E. Levi, Prototype systems for rechargeable magnesium batteries, Nature 407 (2000) 724-727, https://doi.org/10.1038/35037553.

[21] C. Liebenow, Z. Yang, P. Lobitz, The electrodeposition of magnesium using solutions of organomagnesium halides, amidomagnesium halides and magnesium organoborates, Electrochem. Commun. 2 (2000) 641-645, https://doi.org/ 10.1016/S1388-2481(00)00094-1.

[22] H.S. Kim, T.S. Arthur, G.D. Allred, J. Zajicek, J.G. Newman, A.E. Rodnyansky, A. G. Oliver, W.C. Boggess, J. Muldoon, Structure and compatibility of a magnesium electrolyte with a sulphur cathode ,, Nat. Commun. 2 (2011), 427, https://doi. org/10.1038/ncomms1435.
[23] C. Liao, N. Sa, B. Key, A.K. Burrell, L. Cheng, L.A. Curtiss, J.T. Vaughey, J.-J. Woo, L. Hu, B. Pan, Z. Zhang, The unexpected discovery of the $\mathrm{Mg}$ (HMDS)2/ $\mathrm{MgCl} 2$ complex as a magnesium electrolyte for rechargeable magnesium batteries, J. Mater. Chem. 3 (2015) 6082-6087, https://doi.org/10.1039/c5ta00118h.

[24] O. Mizrahi, N. Amir, E. Pollak, O. Chusid, V. Marks, H. Gottlieb, L. Larush, E. Zinigrad, D. Aurbach, Electrolyte Solutions with a Wide Electrochemical Window for Rechargeable Magnesium Batteries, J. Electrochem. Soc. 155 (2008) A103-A109, https://doi.org/10.1149/1.2806175.

[25] R.E. Doe, R. Han, J. Hwang, A.J. Gmitter, I. Shterenberg, H.D. Yoo, N. Pour, D. Aurbach, Novel, electrolyte solutions comprising fully inorganic salts with high anodic stability for rechargeable magnesium batteries, Chem. Commun. 50 (2014) 243-245, https://doi.org/10.1039/c3cc47896c.

[26] D. Aurbach, H. Gizbar, A. Schechter, O. Chusid, H.E. Gottlieb, Y. Gofer, I. Goldberg, Electrolyte Solutions for Rechargeable Magnesium Batteries Based on Organomagnesium Chloroaluminate Complexes, J. Electrochem. Soc. 149 (2) (2002) A115-A121, https://doi.org/10.1149/1.1429925.

[27] Y. Guo, F. Zhang, J. Yang, F. Wang, Electrochemical performance of novel electrolyte solutions based on organoboron magnesium salts, Electrochem. Commun. 18 (2012) 24-27, https://doi.org/10.1016/j.elecom.2012.01.026.

[28] R. Mohtadi, M. Matsui, T.S. Arthur, S.-J. Hwang, Magnesium Borohydride: From Hydrogen Storage to Magnesium Battery, Angew. Chem. Int. Ed. 51 (39) (2012) 9780-9783, https://doi.org/10.1002/anie.201204913.

[29] O. Tutusaus, R. Mohtadi, T.S. Arthur, F. Mizuno, E.G. Nelson, Y.V. Sevryugina, An Efficient Halogen-Free Electrolyte for Use in Rechargeable Magnesium Batteries, Angew. Chem. Int. Ed. 54 (27) (2015) 7900-7904, https://doi.org/10.1002/ anie.201412202.

[30] Z. Zhao-Karger, M.E. Gil Bardaji, O. Fuhr, M. Fichtner, A new class of noncorrosive, highly efficient electrolytes for rechargeable magnesium batteries, J. Mater. Chem. 5 (2017) 10815-10820, https://doi.org/10.1039/c7ta02237a.

[31] F. Bertasi, C. Hettige, F. Sepehr, X. Bogle, G. Pagot, K. Vezzù, E. Negro, S. J. Paddison, S.G. Greenbaum, M. Vittadello, V. Di Noto, A Key concept in Magnesium Secondary Battery Electrolytes, ChemSusChem 8 (18) (2015) 3069-3076, https://doi.org/10.1002/cssc.201500339.

[32] F. Bertasi, F. Sepehr, G. Pagot, S.J. Paddison, V. Di Noto, Toward a MagnesiumIodine Battery, Adv. Funct. Mater. 26 (2016) 4860-4865, https://doi.org/ 10.1002/adfm.201601448.

[33] A. Kopač Lautar, J. Bitenc, T. Rejec, R. Dominko, J.-S. Filhol, M.-L. Doublet, Electrolyte Reactivity in the Double Layer in Mg Batteries: An Interface PotentialDependent DFT Study, J. Am. Chem. Soc. 142 (2020) 5146-5153, https://doi. org/10.1021/jacs.9b12474.

[34] S. Ikeda, M. Takahashi, J. Ishikawa, K. Ito, Solid electrolytes with multivalent cation conduction. 1. Conducting species in $\mathrm{MgZrPO}_{4}$ system, Solid State Ionics 23 (1987) 125-129, https://doi.org/10.1016/0167-2738(87)90091-9.

[35] B. Liang, V. Keshishian, S. Liu, E. Yi, D. Jia, Y. Zhou, J. Kieffer, B. Ye, R.M. Laine, Processing liquid-feed flame spray pyrolysis synthesized $\mathrm{Mg}_{0.5} \mathrm{Ce}_{0.2} \mathrm{Zr}_{1.8}\left(\mathrm{PO}_{4}\right)_{3}$ nanopowders to free standing thin films and pellets as potential electrolytes in allsolid-state Mg batteries, Electrochim. Acta 272 (2018) 144-153, https://doi.org/ 10.1016/j.electacta.2018.04.015.

[36] S. Tamura, M. Yamane, Y. Hoshino, N. Imanaka, Highly conducting divalent $\mathrm{Mg}^{2}$ ${ }^{+}$cation solid electrolytes with well-ordered three-dimensional network structure, J. Solid State Chem. 235 (2016) 7-11, https://doi.org/10.1016/j. jssc.2015.12.008.

[37] P. Canepa, S.-H. Bo, G. Sai Gautam, B. Key, W.D. Richards, T. Shi, Y. Tian, Y. Wang, J. Li, G. Ceder, High magnesium mobility in ternary spinel chalcogenides, Nat. Commun. 8 (2017) 1759, https://doi.org/10.1038/s41467 017-01772-1.

[38] S. Higashi, K. Miwa, M. Aoki, K. Takechi, A novel inorganic solid state ion conductor for rechargeable Mg batteries, Chem. Commun. 50 (11) (2014) 1320-1322, https://doi.org/10.1039/C3CC47097K.

[39] R. Le Ruyet, R. Berthelot, E. Salager, P. Florian, B. Fleutot, R. Janot, Investigation of $\mathrm{Mg}\left(\mathrm{BH}_{4}\right)\left(\mathrm{NH}_{2}\right)$-Based Composite Materials with Enhanced $\mathrm{Mg}^{2+}$ Ionic Conductivity, J. Phys. Chem. C 123 (17) (2019) 10756-10763, https://doi.org/ 10.1021/acs.jpcc.9b00616.

[40] E. Roedern, R.-S. Kühnel, A. Remhof, C. Battaglia, Magnesium Ethylenediamine Borohydride as Solid-State Electrolyte for Magnesium Batteries, Sci. Rep. 7 (2017), 46189, https://doi.org/10.1038/srep46189.

[41] M.L. Aubrey, R. Ameloot, B.M. Wiers, J.R. Long, Metal-organic frameworks as solid magnesium electrolytes, Energy Environ. Sci. 7 (2014) 667-671, https:// doi.org/10.1039/C3EE43143F.

[42] V. Di Noto, S. Lavina, G.A. Giffin, E. Negro, B. Scrosati, Polymer electrolytes: Present, past and future, Electrochim. Acta 57 (2011) 4-13, https://doi.org/ 10.1016/j.electacta.2011.08.048.

[43] A. Patrick, M. Glasse, R. Latham, R. Linford, Novel solid state polymeric batteries, Solid State Ionics 18-19 (1986) 1063-1067, https://doi.org/10.1016/0167-2738 (86)90309-7.

[44] L.L. Yang, A.R. McGhie, G.C. Farrington, Ionic Conductivity in Complexes of Poly (ethylene oxide) and $\mathrm{MgCl}_{2}$, J. Electrochem. Soc. 133 (1986) 1380-1385, https:// doi.org/10.1149/1.2108891.

[45] V. Di Noto, S. Lavina, D. Longo, M. Vidali, A novel electrolytic complex based on $\delta-\mathrm{MgCl}_{2}$ and poly(ethylene glycol) 400, Electrochim. Acta 43 (10-11) (1998) 1225-1237, https://doi.org/10.1016/S0013-4686(97)10023-8.

[46] V. Di Noto, M. Fauri, G. De Luca, M. Vidali, A New Magnesium Ion Polymer Battery (poster), in: 9th, 1998. Edinburgh, Scotland, United Kingdom.

[47] V. Di Noto, M. Vittadello, Mechanism of ionic conductivity in poly(ethylene glycol 400$) /\left(\mathrm{MgCl}_{2}\right)_{\mathrm{x}}$ polymer electrolytes: studies based on electrical 
spectroscopy, Solid State Ionics 147 (2002) 309-316, https://doi.org/10.1016/ S0167-2738(02)00016-4.

[48] S. Ramalingaiah, D.S. Reddy, M.J. Reddy, E. Laxminarsaiah, U.V.S. Rao, Conductivity and discharge characteristic studies of novel polymer electrolyte based on PEO complexed with $\mathrm{Mg}\left(\mathrm{NO}_{3}\right)_{2}$ salt, Mater. Lett. 29 (1996) 285-289, https://doi.org/10.1016/S0167-577X(96)00161-9.

[49] V. Di Noto, M. Fauri, Scienza \& Mestieri 4 (1999) 12-14.

[50] A.R. Polu, R. Kumar, AC impedance and dielectric spectroscopic studies of $\mathrm{Mg}^{2}$ ion conducting PVA-PEG blended polymer electrolytes, Bull. Mater. Sci. 34 (2011) 1063-1067, https://doi.org/10.1007/s12034-011-0132-2.

[51] K.M. Anilkumar, B. Jinisha, M. Manoj, S. Jayalekshmi, Poly(ethylene oxide) (PEO) - Poly(vinyl pyrrolidone) (PVP) blend polymer based solid electrolyte membranes for developing solid state magnesium ion cells, Eur. Polym. J. 89 (2017) 249-262, https://doi.org/10.1016/j.eurpolymj.2017.02.004.

[52] R. Manjuladevi, S. Selvasekarapandian, M. Thamilselvan, R. Mangalam, S. Monisha, P.C. Selvin, A study on blend polymer electrolyte based on poly(vinyl alcohol)-poly (acrylonitrile) with magnesium nitrate for magnesium battery, Ionics 24 (2018) 3493-3506, https://doi.org/10.1007/s11581-018-2500-z.

53] R. Manjuladevi, M. Thamilselvan, S. Selvasekarapandian, R. Mangalam, M. Premalatha, S. Monisha, Mg-ion conducting blend polymer electrolyte based on poly(vinyl alcohol)-poly (acrylonitrile) with magnesium perchlorate, Solid State Ionics 308 (2017) 90-100, https://doi.org/10.1016/j.ssi.2017.06.002.

[54] S.-K. Jeong, Y.-K. Jo, N.-J. Jo, Decoupled ion conduction mechanism of poly(vinyl alcohol) based Mg-conducting solid polymer electrolyte, Electrochim. Acta 52 (2006) 1549-1555, https://doi.org/10.1016/j.electacta.2006.02.061.

[55] S. Ramesh, S.-C. Lu, E. Morris, Towards magnesium ion conducting poly (vinylidenefluoride-hexafluoropropylene)-based solid polymer electrolytes with great prospects: Ionic conductivity and dielectric behaviours, J. Taiwan Inst. Chem. Eng. 43 (2012) 806-812, https://doi.org/10.1016/j.jtice.2012.04.004.

[56] R.C. Agrawal, D.K. Sahu, Y.K. Mahipal, R. Ashrafi, Investigations on ion transport properties of hot-press cast magnesium ion conducting Nano-Composite Polymer Electrolyte (NCPE) films: Effect of filler particle dispersal on room temperature conductivity, Mater. Chem. Phys. 139 (2013) 410-415, https://doi.org/10.1016 j.matchemphys. 2012.12.056.

[57] G.G. Kumar, N. Munichandraiah, Reversibility of $\mathrm{Mg} / \mathrm{Mg}^{2+}$ couple in a gel polymer electrolyte, Electrochim. Acta 44 (1999) 2663-2666, https://doi.org/ 10.1016/S0013-4686(98)00388-0.

[58] D. Aurbach, O. Chasid, Y. Gofer, C. Gizbar, High-energy, rechargeable electrochemical cells, 2004, 9/870707.

[59] Y. NuLi, J. Yang, P. Wang, Electrodeposition of magnesium film from BMIMBF ionic liquid, Appl. Surf. Sci. 252 (2006) 8086-8090, https://doi.org/10.1016/j. apsusc. 2005.10.022.

[60] Y. NuLi, J. Yang, R. Wu, Reversible deposition and dissolution of magnesium from BMIMBF$_{4}$ ionic liquid, Electrochem. Commun. 7 (11) (2005) 1105-1110, https:// doi.org/10.1016/j.elecom.2005.07.013.

[61] G.T. Cheek, W.E. O'Grady, S.Z. El Abedin, E.M. Moustafa, F. Endres, Studies on the electrodeposition of magnesium in ionic liquids, J. Electrochem. Soc. 155 (1) (2008) D91-D95, https://doi.org/10.1149/1.2804763.

[62] D. Aurbach, N. Pour, 13 - Non-aqueous electrochemistry of magnesium (Mg), in G. Song (Ed.), Corrosion of Magnesium Alloys, Woodhead Publishing, 2011 pp. 484-515.

[63] F. Bertasi, K. Vezzù, G. Nawn, G. Pagot, V. Di Noto, Interplay Between Structure and Conductivity in 1-Ethyl-3-methylimidazolium tetrafluoroborate $/\left(\delta-\mathrm{MgCl}_{2}\right)_{\mathrm{f}}$ Electrolytes for Magnesium Batteries, Electrochim. Acta 219 (2016) 152-162, https://doi.org/10.1016/j.electacta.2016.09.091.

[64] T.E. Sutto, T. Wong, J. Taft, T. Duncan, $\mathrm{MG}^{2+}$ ION BEHAVIOR IN IONIC LIQUIDS, ECS Trans. 25 (35) (2010) 85-98, https://doi.org/10.1149/1.3414006.

[65] S. Jeremias, G.A. Giffin, A. Moretti, S. Jeong, S. Passerini, Mechanisms of Magnesium Ion Transport in Pyrrolidinium Bis(trifluoromethanesulfonyl)imideBased Ionic Liquid Electrolytes, J. Phys. Chem. C 118 (2014) 28361-28368, https://doi.org/10.1021/jp5071506.

[66] G.A. Giffin, A. Moretti, S. Jeong, S. Passerini, Complex Nature of Ionic Coordination in Magnesium Ionic Liquid-Based Electrolytes: Solvates with Mobil $\mathrm{Mg}^{2+}$ Cations, J. Phys. Chem. C 118 (19) (2014) 9966-9973, https://doi.org/ 10.1021/jp502354h.

[67] F. Bertasi, C. Hettige, S.G. Greenbaum, M. Vittadello, V. Di Noto, Ionic liquid comprising alkaline earth metal, 2013. US201361900522P.

[68] G. Pagot, F. Bertasi, K. Vezzù, F. Sepehr, X. Luo, G. Nawn, E. Negro, S.J. Paddison, V.D. Noto, Three-dimensional Catenated 1-ethyl-3-methylimidazolium Halotitanate Ionic Liquid Electrolytes for Electrochemical Applications, Electrochim. Acta 246 (2017) 914-923, https://doi.org/10.1016/j. electacta.2017.06.089.

[69] Kisu, K.; Kim, S.; Inukai, M.; Oguchi, H.; Takagi, S.; Orimo, S. Magnesium borohydride ammonia-borane as a magnesium ionic conductor. ACS Appl. Energy Mater., DOI: 10.1021/acsaem.0c00113.

[70] R. Mohtadi, F. Mizuno Beilstein, Magnesium batteries: Current state of the art, issues and future perspectives, J. Nanotechnol. 5 (2014) 1291-1311, https://doi org/10.3762/bjnano.5.143.

[71] P. Novák, V. Shklover, R. Nesper, Magnesium Insertion in Vanadium Oxides: A Structural Study, Z. Phys. Chem. 185 (1994) 51-68, https://doi.org/10.1524/ zpch.1994.185.Part_1.051.

[72] P. Novák, J. Desilvestro, Electrochemical Insertion of Magnesium in Metal Oxide and Sulfides from Aprotic Electrolytes, J. Electrochem. Soc. 140 (1993) 140-144, https://doi.org/10.1149/1.2056075.
[73] X. Ji, J. Chen, F. Wang, W. Sun, Y. Ruan, L. Miao, J. Jiang, C. Wang, WaterActivated $\mathrm{VOPO}_{4}$ for Magnesium Ion Batteries, Nano Lett. 18 (2018) 6441-6448, https://doi.org/10.1021/acs.nanolett.8b02854.

[74] J. Song, M. Noked, E. Gillette, J. Duay, G. Rubloff, S.B. Lee, Activation of a $\mathrm{MnO}_{2}$ cathode by water-stimulated $\mathrm{Mg}^{2+}$ insertion for a magnesium ion battery, Phys. Chem. Chem. Phys. 17 (2015) 5256-5264, https://doi.org/10.1039/ C4CP05591H.

[75] G. Pagot, K. Vezzù, A. Nale, M. Fauri, A. Migliori, V. Morandi, E. Negro, V. Di Noto, Chrysalis-Like Graphene Oxide Decorated Vanadium-Based Nanoparticles: An Extremely High-Power Cathode for Magnesium Secondary Batteries, J. Electrochem. Soc. 167 (7) (2020), 070547, https://doi.org/10.1149/19457111/ab7fb4.

[76] M.S. Ding, T. Diemant, R. Jurgen Behm, S. Passerini, G.A. Giffin, Dendrite Growth in Mg Metal Cells Containing Mg(TFSI $)_{2}$ /Glyme Electrolytes, J. Electrochem. Soc. 165 (10) (2018) A1983-A1990, https://doi.org/10.1149/2.1471809jes.

[77] R. Davidson, A. Verma, D. Santos, F. Hao, C. Fincher, S. Xiang, J. Van Buskirk, K. Xie, M. Pharr, P.P. Mukherjee, S. Banerjee, Formation of Magnesium Dendrites during Electrodeposition, ACS Energy Lett. 4 (2019) 375-376, https://doi.org/ 10.1021/acsenergylett.8b02470.

[78] J. Bitenc, K. Pirnat, E. Zagar, A. Randon-Vitanova, R. Dominko, Effect of salts on the electrochemical performance of Mg metal-organic battery, J. Power Sources 430 (2019) 90-94, https://doi.org/10.1016/j.jpowsour.2019.04.114.

[79] M. Jäckle, K. Helmbrecht, M. Smits, D. Stottmeister, A. Groß, Self-diffusion barriers: possible descriptors for dendrite growth in batteries? Energy Environ. Sci. 11 (2018) 3400-3407, https://doi.org/10.1039/C8EE01448E.

[80] A.K. Lautar, D. Kopac, T. Rejec, T. Bancic, R. Dominko, Morphology evolution of magnesium facets : DFT and KMC simulations, Phys. Chem. Chem. Phys. 21 (2019) 2434-2442, https://doi.org/10.1039/C8CP06171H.

[81] T.S. Arthur, N. Singh, M. Matsui, Electrodeposited $\mathrm{Bi}, \mathrm{Sb}$ and $\mathrm{Bi}_{1-\mathrm{x}} \mathrm{Sb}_{\mathrm{x}}$ alloys as anodes for Mg-ion batteries, Electrochem. Commun. 16 (1) (2012) 103-106, https://doi.org/10.1016/j.elecom.2011.12.010.

[82] N. Singh, T.S. Arthur, C. Ling, M. Matsui, F. Mizuno, A high energy-density tin anode for rechargeable magnesium-ion batteries, Chem. Commun. 49 (2) (2013) 149-151, https://doi.org/10.1039/c2cc34673g.

[83] K. Periyapperuma, T.T. Tran, M.I. Purcell, M.N. Obrovac, The reversible magnesiation of Pb, Electrochim. Acta 165 (2015) 162-165, https://doi.org/ 10.1016/j.electacta.2015.03.006.

[84] F. Murgia, E.T. Weldekidan, L. Stievano, L. Monconduit, R. Berthelot, First investigation of indium-based electrode in Mg battery, Electrochem. Commun. 60 (2015) 56-59, https://doi.org/10.1016/j.elecom.2015.08.007.

[85] L. Wang, S.S. Welborn, H. Kumar, M. Li, Z. Wang, V.B. Shenoy, E. Detsi, Magnesium-Ion Batteries: High-Rate and Long Cycle-Life Alloy-Type MagnesiumIon Battery Anode Enabled Through (De)magnesiation-Induced Near-RoomTemperature Solid-Liquid Phase Transformation, Adv. Energy Mater. 9 (45) (2019), 1970180, https://doi.org/10.1002/aenm.201970180.

[86] F. Murgia, L. Monconduit, L. Stievano, R. Berthelot, Electrochemical magnesiation of the intermetallic InBi through conversion-alloying mechanism, Electrochim. Acta 209 (2016) 730-736, https://doi.org/10.1016/j. electacta.2016.04.020

[87] F. Murgia, D. Laurencin, E.T. Weldekidan, L. Stievano, L. Monconduit, M.L. Doublet, R. Berthelot, Electrochemical Mg alloying properties along the Sb1XBix solid solution, Electrochim. Acta 259 (2018) 276-283, https://doi.org/ 10.1016/j.electacta.2017.10.170.

[88] L. Blondeau, E. Foy, H. Khodja, M. Gauthier, Unexpected behavior of the InSb alloy in Mg-ion batteries: unlocking the reversibility of Sb, J. Phys. Chem. C 123 (2) (2019) 1120-1126, https://doi.org/10.1021/acs.jpcc.8b10913.

[89] J. Niu, H. Gao, W. Ma, F. Luo, K. Yin, Z. Peng, Z. Zhang, Dual phase enhanced superior electrochemical performance of nanoporous bismuth-tin alloy anodes for magnesium-ion batteries, Energy Storage Mater. 14 (2018) 351-360, https://doi. org/10.1016/j.ensm.2018.05.023.

[90] J. Niu, K. Yin, H. Gao, M. Song, W. Ma, Z. Peng, Z. Zhang, Composition- and sizemodulated porous bismuth-tin biphase alloys as anodes for advanced magnesium ion batteries, Nanoscale 11 (2019) 15279-15288, https://doi.org/10.1039/ C9NR05399A.

[91] M. Song, J. Niu, K. Yin, H. Gao, C. Zhang, W. Ma, F. Luo, Z. Peng, Z. Zhang, Selfsupporting, eutectic-like, nanoporous biphase bismuth-tin film for highperformance magnesium storage, Nano Res. 12 (2019) 801-808, https://doi.org/ 10.1007/s12274-019-2291-1.

[92] L.R. Parent, Y. Cheng, P.V. Sushko, Y. Shao, J. Liu, C.-M. Wang, N.D. Browning, Realizing the Full Potential of Insertion Anodes for Mg-Ion Batteries Through the Nanostructuring of Sn, Nano Lett. 15 (2015) 1177-1182, https://doi.org/ $10.1021 / \mathrm{nl} 5042534$

[93] L. Blondeau, S. Surblé, E. Foy, H. Khodja, M. Gauthier, Electrochemical reactivity of In-Pb solid solution as a negative electrode for rechargeable Mg-ion batteries, J. Energy Chem. 55 (2021) 124-128, https://doi.org/10.1016/j. jechem.2020.07.004.

[94] Y. Shao, M. Gu, X. Li, Z. Nie, P. Zuo, G. Li, T. Liu, J. Xiao, Y. Cheng, C. Wang, et al., Highly reversible $\mathrm{Mg}$ insertion in nanostructured $\mathrm{Bi}$ for $\mathrm{Mg}$ ion batteries, Nano Lett. 14 (1) (2013) 255-260, https://doi.org/10.1021/nl403874y.

[95] Z. Liu, J. Lee, G. Xiang, H.F.J. Glass, E.N. Keyzer, S.E. Dutton, C.P. Grey, Insights into the electrochemical performances of $\mathrm{Bi}$ anodes for $\mathrm{Mg}$ ion batteries using ${ }^{25} \mathrm{Mg}$ solid state NMR spectroscopy, Chem. Commun. 53 (4) (2017) 743-746, https://doi.org/10.1039/C6CC08430C.

[96] F. Murgia, L. Stievano, L. Monconduit, R. Berthelot, Insight into the electrochemical behavior of micrometric $\mathrm{Bi}$ and $\mathrm{Mg}_{3} \mathrm{Bi}_{2}$ as high performance 
negative electrodes for Mg batteries, J. Mater. Chem. A 3 (32) (2015) 16478-16485, https://doi.org/10.1039/C5TA04077A.

[97] D.-T. Nguyen, X.M. Tran, J. Kang, S.-W. Song, Magnesium storage performance and surface film Formation behavior of tin anode material, ChemElectroChem 3 (11) (2016) 1813-1819, https://doi.org/10.1002/celc.201600400.

[98] Y.-H. Tan, W.-T. Yao, T. Zhang, T. Ma, L.-L. Lu, F. Zhou, H.-B. Yao, S.-H. Yu, High voltage magnesium-ion battery enabled by nanocluster $\mathrm{Mg}_{3} \mathrm{Bi}_{2}$ alloy anode in noncorrosive electrolyte, ACS Nano 12 (6) (2018) 5856-5865, https://doi.org/ 10.1021/acsnano.8b01847.

[99] Z. Meng, D. Foix, N. Brun, R. Dedryvère, L. Stievano, M. Morcrette, R. Berthelot Alloys to replace $\mathrm{Mg}$ anodes in efficient and practical $\mathrm{Mg}$-Ion/Sulfur batteries, ACS Energy Lett. 4 (9) (2019) 2040-2044, https://doi.org/10.1021/ acsenergylett.9b01389.

[100] A. Darwiche, C. Marino, M.T. Sougrati, B. Fraisse, L. Stievano, L. Monconduit, Better cycling performances of bulk Sb in Na-ion batteries compared to Li-ion systems: an unexpected electrochemical mechanism, J. Am. Chem. Soc. 134 (2012) 20805-20811, https://doi.org/10.1021/ja310347x.

[101] L. Baggetto, P. Ganesh, C.-N. Sun, R.A. Meisner, T.A. Zawodzinski, G.M. Veith, Intrinsic thermodynamic and kinetic properties of Sb electrodes for Li-ion and $\mathrm{Na}$ ion batteries: experiment and theory, J. Mater. Chem. A 1 (2013) 7985-7994, https://doi.org/10.1039/C3TA11568B.

[102] A. Darwiche, R. Dugas, B. Fraisse, L. Monconduit, Reinstating lead for highloaded efficient negative electrode for rechargeable sodium-ion battery, J. Power Sources 304 (2016) 1-8, https://doi.org/10.1016/j.jpowsour.2015.10.087.

[103] X. Liang, Q. Pang, I.R. Kochetkov, M.S. Sempere, H. Huang, X. Sun, L.F. Nazar, A facile surface chemistry route to a stabilized lithium metal anode, Nat. Energy 2 (2017), 17119, https://doi.org/10.1038/nenergy.2017.119.

[104] S. Choudhury, Z. Tu, S. Stalin, D. Vu, K. Fawole, D. Gunceler, R. Sundararaman, L. A. Archer, Electroless formation of hybrid lithium anodes for fast interfacial ion transport, Angew. Chemie - Int. Ed. 56 (42) (2017) 13070-13077, https://doi. org/10.1002/anie.201707754.

[105] Z. Tu, S. Choudhury, M.J. Zachman, S. Wei, K. Zhang, L.F. Kourkoutis, L. A. Archer, Fast ion transport at solid-solid interfaces in hybrid in hybrid battery anodes, Nat. Energy 3 (2018) 310-316, https://doi.org/10.1038/s41560-0180096-1.

[106] R. Lv, X. Guan, J. Zhang, Y. Xia, J. Luo, Enabling Mg metal anodes rechargeable in conventional electrolytes by fast ionic transport interphase, Natl. Sci. Rev. 7 (2) (2020) 333-341, https://doi.org/10.1093/nsr/nwz157.

[107] M.D. Levi, E. Lancri, E. Levi, H. Gizbar, Y. Gofer, D. Aurbach, The effect of the anionic framework of $\mathrm{Mo}_{6} \mathrm{X}_{8}$ Chevrel Phase $(\mathrm{X}=\mathrm{S}, \mathrm{Se})$ on the thermodynamics and the kinetics of the electrochemical insertion of $\mathrm{Mg}^{2+}$ ions,, Solid State Ionics 176 (2005) 1695-1699, https://doi.org/10.1016/j.ssi.2005.04.019.

[108] X. Sun, P. Bonnick, L.F. Nazar, Layered $\mathrm{TiS}_{2}$ positive electrode for Mg batteries, ACS Energy Lett. 1 (1) (2016) 297-301, https://doi.org/10.1021/ acsenergylett.6b00145.

[109] Z.-L. Tao, L.-N. Xu, X.-L. Gou, J. Chen, H.-T. Yuan, TiS 2 nanotubes as the cathode materials of Mg-ion batteries, Chem. Commun. (2004) 2080-2081, https://doi. org/10.1039/B403855J.

[110] X. Sun, P. Bonnick, V. Duffort, M. Liu, Z. Rong, K.A. Persson, G. Ceder, L.F. Nazar A high capacity thiospinel cathode for Mg batteries,, Energy Environ. Sci. 9 (2016) 2273-2277, https://doi.org/10.1039/C6EE00724D.

[111] Y. Liang, R. Feng, S. Yang, H. Ma, J. Liang, J. Chen, Rechargeable Mg batteries with graphene-like MoS2 cathode and ultrasmall Mg nanoparticle anode, Adv. Mater. 23 (2011) 640-643, https://doi.org/10.1002/adma.201003560.

[112] Y. Gu, Y. Katsura, T. Yoshino, H. Takagi, K. Taniguchi, Rechargeable magnesiumion battery based on a TiSe2-cathode with d-p orbital hybridized electronic structure, Sci. Rev. 12486 (5) (2015), https://doi.org/10.1038/srep12486.

[113] B. Liu, T. Luo, G. Mu, X. Wang, D. Chen, G. Shen, Rechargeable Mg-ion batteries based on WSe2 nanowire cathodes, ACS Nano 7 (2013) 8051-8058, https://doi org/10.1021/nn4032454.

[114] Z. Li, B.P. Vinayan, P. Jankowski, C. Njel, A. Roy, T. Vegge, J. Maibach, J.M. G. Lastra, M. Fichtner, Z. Zhao-Karger, Multi-Electron Reactions Enabled by Anion-Based Redox Chemistry for High-Energy Multivalent Rechargeable Batteries, Angew. Chemie Int. Ed. 59 (28) (2020) 11483-11490, https://doi.org/ 10.1002/anie. 202002560.

[115] A. Manthiram, J.B. Goodenough, Lithium insertion into $\mathrm{Fe}_{2}\left(\mathrm{SO}_{4}\right)_{3}$ frameworks, J. Power Sources 26 (3-4) (1989) 26-403, https://doi.org/10.1016/0378-7753 (89)80153-3.

[116] G. Sai Gautam, P. Canepa, A. Abdellahi, A. Urban, R. Malik, G. Ceder, The intercalation phase diagram of $\mathrm{Mg}$ in $\mathrm{V}_{2} \mathrm{O}_{5}$ from first-principles, Chem. Mater. 27 (10) (2015) 3733-3742, https://doi.org/10.1021/acs.chemmater.5b00957.

[117] J.L. Andrews, A. Mukherjee, H.D. Yoo, A. Parija, P.M. Marley, S. Fakra, D. Prendergast, J. Cabana, R.F. Klie, S. Banerjee, Reversible Mg-ion insertion in a metastable one-dimensional polymorph of $\mathrm{V}_{2} \mathrm{O}_{5}$, Inside Chem. 4 (2018) 564-585, https://doi.org/10.1016/j.chempr.2017.12.018.

[118] N. Sa, H. Wang, D.L. Proffit, A.L. Lipson, B. Key, M. Liu, Z. Feng, T.T. Fister, Y. Ren, C.-J. Sun, J.T. Vaughey, P.A. Fenter, K.A. Persson, A.K. Burrell, Is alpha$\mathrm{V}_{2} \mathrm{O}_{5}$ a cathode material for Mg insertion batteries? J. Power Sources 323 (2016) 44-50, https://doi.org/10.1016/j.jpowsour.2016.05.028.

[119] G. Gershinsky, H.D. Yoo, Y. Gofer, D. Aurbach, Electrochemical, Spectroscopic Analysis, Of $\mathrm{Mg}^{2+}$ intercalation into thin film electrodes of layered oxides: $\mathrm{V}_{2} \mathrm{O}_{5}$ and $\mathrm{MoO}_{3}$, Langmuir 29 (2013) 10964-10972, https://doi.org/ 10.1021/la402391f.

[120] K.W. Nam, S. Kim, S. Lee, M. Salama, I. Shterenberg, Y. Gofer, J.-S. Kim, E. Yang, C.S. Park, J.-S. Kim, S.-S. Lee, W.-S. Chang, S.-G. Doo, Y.N. Jo, Y. Jung, D. Aurbach, J.W. Choi, The high performance of crystal water containing manganese birnessite cathodes for magnesium batteries,, Nano Lett. 15 (6) (2015) 4071-4079, https://doi.org/10.1021/acs.nanolett.5b01109.

[121] R. Zhang, X. Yu, K.-W. Nam, C. Ling, T.S. Arthur, W. Song, A.M. Knapp, S. N. Ehrlich, X.-Q. Yang, M. Matsui, $\alpha-\mathrm{MnO}_{2}$ as a cathode material for rechargeable Mg batteries, Electrochem. Commun. 23 (2012) 110-113, https://doi.org/ 10.1016/j.elecom.2012.07.021.

[122] R. Zhang, T.S. Arthur, C. Ling, F. Mizuno, Manganese dioxides as rechargeable magnesium battery cathode; synthetic approach to understand magnesiation process, J. Power Sources 282 (2015) 630-638, https://doi.org/10.1016/j. jpowsour.2015.02.067.

[123] R. Zhang, C. Ling, Unveil the chemistry of olivine $\mathrm{FePO}_{4}$ as magnesium battery cathode, ACS Appl. Mater. Interfaces 8 (2016) 18018-18026, https://doi.org/ 10.1021/acsami.6b03297.

[124] J. Zeng, Y. Yang, S. Lai, J. Huang, Y. Zhang, J. Wang, J. Zhao, A promising highvoltage cathode material based on mesoporous $\mathrm{Na}_{3} \mathrm{~V}_{2}(\mathrm{PO} 4)_{3} / \mathrm{C}$ for rechargeable magnesium batteries, Chem. Eur J. 23 (2017) 16898-16905, https://doi.org/ 10.1002/chem.201704303.

[125] Z. Feng, J. Yang, Y. NuLi, J. Wang, X. Wang, Z. Wang, Preparation and electrochemical study of a new magnesium intercalation material $\mathrm{Mg}_{1.03} \mathrm{Mn}_{0.97} \mathrm{SiO}_{4}$, Electrochem. Commun. 10 (2008) 1291-1294, https://doi org/10.1016/j.elecom.2008.06.021.

[126] T. Ichitsubo, T. Adachi, S. Yagi, T. Doi, Potential positive electrodes for high voltage magnesium-ion batteries, J. Mater. Chem. 21 (2011) 11764-11772, https://doi.org/10.1039/C1JM11793A.

[127] L. Li, Y. Lu, Q. Zhang, S. Zhao, Z. Hu, S.-L. Chou, Recent Progress on Layered Cathode Materials for Nonaqueous Rechargeable Magnesium Batteries, Small (2019), 1902767, https://doi.org/10.1002/smll.201902767.

[128] S. Rasul, S. Suzuki, S. Yamaguchi, M. Miyayama, High capacity positive electrodes for secondary Mg-ion batteries, Electrochim. Acta 82 (2012) 243-249, https://doi.org/10.1016/j.electacta.2012.03.095.

[129] R. Zhang, T.S. Arthur, C. Ling, F. Mizuno, Manganese dioxides as rechargeable magnesium battery cathode; synthetic approach to understand magnesiation process, J. Power Sources 282 (2015) 630-638, https://doi.org/10.1016/j. jpowsour.2015.02.067.

[130] P. Canepa, G. Sai Gautam, D.C. Hannah, R. Malik, M. Liu, K.G. Gallagher, K. A. Persson, G. Ceder, Odyssey of multivalent cathode materials: open questions and future challenges, Chem. Rev. 117 (5) (2017), https://doi.org/10.1021/acs. chemrev.6b00614.

[131] Z. Rong, R. Malik, P. Canepa, G. Sai Gautam, M. Liu, A. Jain, K. Persson, G. Ceder, Materials design rules for multivalent ion mobility in intercalation structures, Chem. Mater. 27 (17) (2015) 6016-6021, https://doi.org/10.1021/acs. chemmater.5b02342.

[132] W. K, S. Nam, S. Kim, M. Lee, I. Salama, Y. Shterenberg, J.-S. Gofer, E. Kim, C. S. Yang, J.-S. Park, S.-S. Kim, W.-S. Lee, S.-G. Chang, Y.N. Doo, Y. Jo, D. Jung, J. Aurbach, W. Choi, The High Performance of Crystal Water Containing Manganese Birnessite Cathodes for Magnesium Batteries, Nano Lett. 15 (6) (2015) 4071-4079, https://doi.org/10.1021/acs.nanolett.5b01109.

[133] N.N. Sinha, N. Munichandraiah, Electrochemical conversion of $\mathrm{LiMn}_{2} \mathrm{O}_{4}$ to $\mathrm{MgMn}_{2} \mathrm{O}_{4}$ in aqueous electrolytes, Electrochem. Solid-State Lett. 11 (2008) F23, https://doi.org/10.1149/1.2972990.

[134] G. Sai Gautam, P. Canepa, W.D. Richards, R. Malik, G. Ceder, Role of structural $\mathrm{H} 2 \mathrm{O}$ in intercalation electrodes: the case of $\mathrm{Mg}$ in nanocrystalline xerogel- $\mathrm{V}_{2} \mathrm{O}_{5}$, Nano Lett. 16 (2016) 2426-2431, https://doi.org/10.1021/acs. nanolett.5b05273.

[135] J. Koketsu, B.J. Ma, M. Morgan, C. Body, W. Legein, Dachraoui M. Giannini, A. Demortière, M. Salanne, F. Dardoize, H. Groult, O.J. Borkiewicz, K. W. Chapman, P. Strasser, D. Dambournet, Reversible magnesium and aluminium ions insertion in cation-deficient anatase $\mathrm{TiO}_{2}$, Nat. Mater. 16 (2017) 1142-1148, https://doi.org/10.1038/nmat4976.

[136] A. Robba, A. Vizintin, J. Bitenc, G. Mali, I. Arčon, M. Kavčič, M. Žitnik, K. Bučar, G. Aquilanti, C. Martineau-Corcos, A. Randon-Vitanova R, Mechanistic Study of Magnesium-Sulfur Batteries, Chem. Mater. 29 (21) (2017) 9555-9564, https:// doi.org/10.1021/acs.chemmater.7b03956.

[137] Y. Nakayama, R. Matsumoto, K. Kumagae, D. Mori, Y. Mizuno, S. Hosoi, K. Kamiguchi, N. Koshitani, Y. Inaba, H. Kudo, E.C. Kawasaki, Miller J. Nelson Weker, M.F. Toney, Zinc Blende Magnesium Sulfide in Rechargeable MagnesiumSulfur Batteries, Chem. Mater. 30 (18) (2018) 6318-6324, https://doi.org/ 10.1021/acs.chemmater.8b02105.

[138] X. Yu, A. Manthiram, Performance Enhancement and Mechanistic Studies of Magnesium-Sulfur Cells with an Advanced Cathode Structure, ACS Energy Lett. 1 (2) (2016) 431-437, https://doi.org/10.1021/acsenergylett.6b00213.

[139] T. Gao, S. Hou, F. Wang, Z. Ma, X. Li, K. Xu, C. Wang, Reversible $\mathrm{S}_{0} / \mathrm{MgS}_{\mathrm{X}}$ Redox Chemistry in a MgTFSI $2 / \mathrm{MgCl}_{2} / \mathrm{DME}$ Electrolyte for Rechargeable $\mathrm{Mg} / \mathrm{S}$ Batteries, Angew. Chemie Int. Ed. 56 (2017) 13526-13530, https://doi.org/ 10.1002/anie.201708241.

[140] Z. Zhang, Z. Cui, L. Qiao, J. Guan, H. Xu, X. Wang, P. Hu, H. Du, S. Li, X. Zhou, S. Dong, Z. Liu, G. Cui, L. Chen, Novel Design Concepts of Efficient Mg-Ion Electrolytes toward High-Performance Magnesium-Selenium and Magnesium-Sulfur Batteries, Adv. Energy Mater. 7 (2017) 1602055, https://doi. org/10.1002/aenm.201602055.

[141] A. Du, Z. Zhang, H. Qu, Z. Cui, L. Qiao, L. Wang, J. Chai, T. Lu, S. Dong, T. Dong, H. Xu, X. Zhou, G. Cui, An efficient organic magnesium borate-based electrolyte with non-nucleophilic characteristics for magnesium-sulfur battery, Energy Environ. Sci. 10 (2017) 2616-2625, https://doi.org/10.1039/C7EE02304A.

[142] A. Robba, M. Mežnar, A. Vizintin, J. Bitenc, J. Bobnar, I. Arčon, A. RandonVitanova, R. Dominko, Role of Cu current collector on electrochemical 
mechanism of Mg-S battery, J. Power Sources 450 (2020), 227672, https://doi. org/10.1016/j.jpowsour.2019.227672.

[143] H. Tian, T. Gao, X. Li, X. Wang, C. Luo, X. Fan, C. Yang, L. Suo, Z. Ma, W. Han, C. Wang, High power rechargeable magnesium/iodine battery chemistry, Nat. Commun 8 (2017), 14083, https://doi.org/10.1038/ncomms14083.

[144] J. Bitenc, K. Pirnat, T. Bančič, M. Gaberšček, B. Genorio, A. Randon-Vitanova, R. Dominko, Anthraquinone-based polymer as cathode in rechargeable magnesium batteries, ChemSusChem 8 (24) (2015) 4128-4132, https://doi.org/ 10.1002/cssc.201500910.

[145] J. Bitenc, K. Pirnat, G. Mali, B. Novosel, A. Randon Vitanova, R. Dominko, Poly (hydroquinoyl-benzoquinonyl sulfide) as an active material in $\mathrm{Mg}$ and $\mathrm{Li}$ organic batteries, Electrochem. Commun. 69 (2016) 1-5, https://doi.org/10.1016/j. elecom.2016.05.009.

[146] B. Pan, J. Huang, Z. Feng, L. Zeng, M. He, L. Zhang, J.T. Vaughey, M.J. Bedzyk, P. Fenter, Z. Zhang, A.K. Burrell, C. Liao, Polyanthraquinone-Based Organic Cathode for High-Performance Rechargeable Magnesium-Ion Batteries, Adv. Energy Mater. 6 (2016) 1600140, https://doi.org/10.1002/aenm.201600140.

[147] A. Vizintin, J. Bitenc, A. Kopač Lautar, J. Grdadolnik, A. Randon Vitanova, K. Pirnat, Redox Mechanisms in Li and Mg Batteries Containing Poly (phenanthrene quinone)/Graphene Cathodes using Operando ATR-IR Spectroscopy, ChemSusChem 13 (2020) 2328-2336, https://doi.org/10.1002/ cssc. 202000054 .

[148] T. Bančič, J. Bitenc, K. Pirnat, A. Kopač Lautar, J. Grdadolnik, A. Randon Vitanova, R. Dominko, Electrochemical performance and redox mechanism of naphthalene-hydrazine diimide polymer as a cathode in magnesium battery, J. Power Sources 395 (2018) 25-30, https://doi.org/10.1016/j. jpowsour.2018.05.051.

[149] C. Wang, X. Fan, F. Wang, X. Ji, R. Wang, T. Gao, S. Hou, J. Chen, T. Deng, X. Li, L. Chen, C. Luo, L. Wang, A Universal Organic Cathode for Ultrafast Li- and Multivalent Metal Batteries, Angew. Chemie. 57 (24) (2018) 7146-7150, https:// doi.org/10.1002/ange.201803703.
[150] L. Chen, J.L. Bao, X. Dong, D.G. Truhlar, Y. Wang, C. Wang, Y. Xia, Aqueous MgIon Battery Based on Polyimide Anode and Prussian Blue Cathode, ACS Energy Lett. 2 (5) (2017) 1115-1121, https://doi.org/10.1021/acsenergylett.7b00040.

[151] D. Lu, H. Liu, T. Huang, Z. Xu, L. Ma, P. Yang, P. Qiang, F. Zhang, D. Wu, Magnesium ion based organic secondary batteries, J. Mater. Chem. A 6 (2018) 17297-17302, https://doi.org/10.1039/C8TA05230A.

[152] A. Vizintin, J. Bitenc, A. Kopač lautar, K. Pirnat, J. Grdadolnik, J. Stare, A. RadonVitanova, R. Dominko, Probing electrochemical reactions in organic cathode materials via in operando infrared spectroscopy, Nat. Commun. 661 (2018) 9, https://doi.org/10.1038/s41467-018-03114-1.

[153] J. Bitenc, T. Pavčnik, U. Košir, K. Pirnat, Quinone Based Materials as Renewable High Energy Density Cathode Materials for Rechargeable Magnesium Batteries, Materials 13 (3) (2020), 506, https://doi.org/10.3390/ma13030506.

[154] H. Dong, Y. Liang, O. Tutusaus, R. Mohtadi, Y. Zhang, F. Hao, Y. Yao, Directing Mg-Storage Chemistry in Organic Polymers toward High-Energy Mg Batteries, Joule 3 (3) (2019) 782-793, https://doi.org/10.1016/j.joule.2018.11.022.

[155] J. Bitenc, A. Vizintin, J. Grdadolnik, R. Dominko, Tracking electrochemical reactions inside organic electrodes by operando IR spectroscopy, Energy Storage Mater. 21 (2019) 347-353, https://doi.org/10.1016/j.ensm.2019.05.038.

[156] M. Vittadello, S. Biscazzo, S. Lavina, M. Fauri, V. Di Noto, Vibrational studies of the ion-polymer interactions in $\alpha$-hydro- $\omega$-oligo(oxyethylene) hydroxy-poly[oligo (oxyethylene)oxydimethylsililene]/8-MgCl2, Solid State Ionics 147 (2002) 341-347.

[157] V. Di Noto, V. Munchow, M. Vittadello, J.C. Collet, S. Lavina, Synthesis, characterization and conductivity studies of $\mathrm{Li}$ and $\mathrm{Mg}$ polymer electrolytes based on esters of ethylenediaminetetraacetic acid and PEG400, Solid State Ionics 147 (2002) 397-402.

[158] V. Di Noto, Electrical Spectroscopy Studies of Lithium and Magnesium Polymer Electrolytes Based on PEG400, J. Phys. Chem. B 106 (2002) 11139-11154. 